Research Article

\title{
Optimal Sizing of Isolated Microgrid Containing Photovoltaic/Photothermal/Wind/Diesel/Battery
}

\author{
Guo Zhao $\mathbb{D}^{1,2}$ Tianhua Cao, ${ }^{1,2}$ Yudan Wang, ${ }^{3}$ Huirui Zhou, ${ }^{1,2}$ Chi Zhang, ${ }^{1,2}$ \\ and Chenxi Wan ${ }^{1,2}$ \\ ${ }^{1}$ School of Electrical and Electronic Engineering, Hubei University of Technology, Wuhan 430068, China \\ ${ }^{2}$ Hubei Key Laboratory for High-Efficiency Utilization of Solar Energy and Operation Control of Energy Storage System, \\ Hubei University of Technology, Wuhan 430068, China \\ ${ }^{3}$ Department of Mechanical and Electrical Engineering, Wenhua College, Wuhan 430074, China
}

Correspondence should be addressed to Guo Zhao; zhaoguo@hbut.edu.cn

Received 27 January 2021; Revised 24 May 2021; Accepted 6 August 2021; Published 18 August 2021

Academic Editor: Yuanzuo Li

Copyright (c) 2021 Guo Zhao et al. This is an open access article distributed under the Creative Commons Attribution License, which permits unrestricted use, distribution, and reproduction in any medium, provided the original work is properly cited.

The establishment of isolated microgrid is of great significance in solving power supply problems in offshore islands or remote mountainous areas. Aiming at the isolated microgrid containing photovoltaic, photothermal, wind, diesel, and energy storage, a three-objective sizing optimization model of the microgrid is proposed considering comprehensive economy cost, deficiency of power supply probability (DPSP), and renewable energy discard rate (REDR). The three-objective sizing optimization model was solved by the improved multiobjective grey wolf optimization algorithm. An island was taken as an example to optimize the sizing of the microgrid, and the rationality of the proposed three-objective model was verified. The feasibility of the improved multiobjective grey wolf optimization (IMOGWO) was verified by comparing with the multiobjective grey wolf optimization (MOGWO). Three representative solution sets and a set of compromise solution sets are obtained by simulation, and the results satisfied the load demand. And the DPSP and the REDR are reduced by $7.55 \%$ and $6.29 \%$ by using the IMOGWO. The designed and analyzed hybrid renewable energy system model might be applicable to around the world having similar climate conditions.

\section{Introduction}

With the rapid development of the current society, the demand for electrical energy is increasing. Due to the nonrenewability of fossil fuels and the increasing attention of people on the environmental protection [1], clean energy such as solar and wind energy has begun to be applied in the power generation system on a large scale. Microgrid has attracted people's attention because of its green and convenient features. Microgrid is usually a small generation and distribution system composed of distributed power sources, energy storage devices, energy conversion devices, and loads, and it has broad development prospects because it can improve the flexibility of the grid and reliability of power supply [2, $3]$. It is worth studying that how to configure the size of the distributed power supply to meet the load demand and minimize the comprehensive economic cost, deficiency of power supply probability, and renewable energy discard rate.

The optimization of microgrid capacity has been widely studied. Ref. [4] established a microgrid containing wind, photovoltaic, energy storage, and fuel cells. A multi-objective optimization model of annual investment cost, $\mathrm{CO} 2$ emissions, and converter loss of microgrid was established considering electrothermal coupling. Multiobjective particle swarm optimization was used to solve the problem. Ref. [5] established a microgrid containing wind, photovoltaic, and energy storage. The environmental impact was converted into economic index and added into the comprehensive economic cost to form a single objective function. The improved bacterial foraging algorithm was used to solve the problem. Ref. [6] 
established a microgrid containing wind, photovoltaic, and energy storage. The objective function is modified by the self-adaptive penalty method. The hybrid quantum genetic algorithm was used to solve the problem. Ref. [7] established a microgrid containing wind, photovoltaic, and energy storage. A two-layer optimization model of energy storage system capacity investment costs and microgrid operating costs was established considering the coupling effects of multitime-scale uncertainties. The compound differential evolution algorithm was used to solve the problem. Ref. [8] established a microgrid containing wind, photovoltaic, energy storage, and diesel generator. An optimization allocation idea of microgrid capacity was proposed based on sensitivity analysis. Taking economy as the objective function, the nondominated sorting genetic algorithm was used to obtain the optimal result. Ref. [9] established a microgrid containing wind, photovoltaic, and energy storage. The firefly-inspired algorithm was used to solve the problem considering the standard of load dissatisfaction rate, power reliability, and system cost indicators. The effectiveness of the algorithm is verified by a practical example. Ref. [10] established a microgrid containing wind, photovoltaic, energy storage, and diesel generator. The comprehensive economic cost, renewable energy power generation rate, and pollutant emissions were converted into a single objective function through the linear weighting method. The genetic algorithm was used to solve the problem. Ref. [11] established a microgrid containing wind, photovoltaic, energy storage, and diesel generator. Taking comprehensive economic cost and power supply reliability as the dual optimization goals, the grasshopper optimization algorithm was used to solve the problem. The superiority of the algorithm was verified by comparing with the cuckoo search algorithm and the particle swarm optimization. Ref. [12] established a multienergy microgrid with wind, photovoltaic, energy storage, and diesel generator and biomass. Taking comprehensive economic costs and environmental protection factors as the dual optimization goals, ant colony optimization was used to solve the problem. The feasibility of the proposed algorithm is verified by comparing with genetic algorithm and particle swarm optimization. Ref. [13] takes a rural medical center in Nigeria as an example to establish a microgrid containing wind, photovoltaic, energy storage, and diesel generator. Taking economic cost as the optimization objective, HOMER is used for optimization simulation to get the optimal results. Ref. [14] used the linear weighting method to convert the economic cost, voltage deviation, and voltage stability index into a single optimization objective. Considering the random variation of solar radiation and load demand, a Modified Ant Lion Optimization (MALO) was used to get the optimal sizing of PV-DG and DSTATCOM systems.

The above researches on the optimal sizing and solution methods of the microgrid renewable energy power generation system have gotten certain results, but there are still some limitations. For distributed power sources of microgrid, most researches focus on wind, photovoltaic, energy storage, and diesel generator, but there are few researches on photothermal power generation. Although solar photovoltaic and wind energy resources are complementary, they both have intermittent availability. The solar thermal power generation system is equipped with a thermal storage system, which can store the superheated steam output by the thermal absorber in the thermal storage system; then, it can effectively avoid excessive energy discarding. The stored heat can be used when the power generation is insufficient, which can also improve the power supply reliability of system. For optimization goals, there are many researches on single optimization objective and dual optimization objective, but there are few researches on three-objective optimization problems. The traditional dual-objective optimization model cannot meet the actual needs with the increasing requirements of the state and power enterprises for renewable energy generation; so, it is necessary to add renewable energy generation rate into the optimization objective. For optimization algorithms, most researches use genetic algorithm and its improved algorithm or particle swarm optimization and its improved algorithm. And the above algorithms generally have problems such as slow convergence speed, many iterations, easy to fall into local optimum, poor stability, and low solution accuracy. The grey wolf optimizer (GWO) has the characteristics of simple structure, less need to adjust the parameters, and easy implementation. Among them, there are convergence factors that can be adjusted adaptively and an information feedback mechanism, which can achieve a balance between local optimization and global search. It has good performance in terms of solution accuracy and convergence speed.

Therefore, this paper establishes an isolated microgrid containing photovoltaic, photothermal, wind, diesel generator, and energy storage according to the situation of wind and solar resources in a certain place. And a three-objective optimization model of comprehensive economic cost, deficiency of power supply probability, and renewable energy discard rate is established. An improved multiobjective grey wolf optimization algorithm is proposed to solve the model, and an island is taken as an example to verify the feasibility of the proposed algorithm. The main contributions of the paper are as follows:

(i) Establishing a microgrid system containing photovoltaic, photothermal, wind turbine, diesel generator, energy storage, and load

(ii) Proposing an optimal sizing method based on IMOGWO

(iii) The mathematical model of the optimal planning problem is formulated as a multiobjective optimization problem that includes the comprehensive economy cost, deficiency of power supply probability, and renewable energy discard rate

The rest of paper is organized as follows: Section 2 presents the output model of distributed power supply. Section 3 introduces the energy allocation strategy of this paper. Section 4 defines the problem formulation and the system constraints. Section 5 presents the mathematical formulation of GWO, MOGWO, and IMOGWO techniques. Section 6 presents the numerical results. Finally, the conclusions presented in Section 7. 


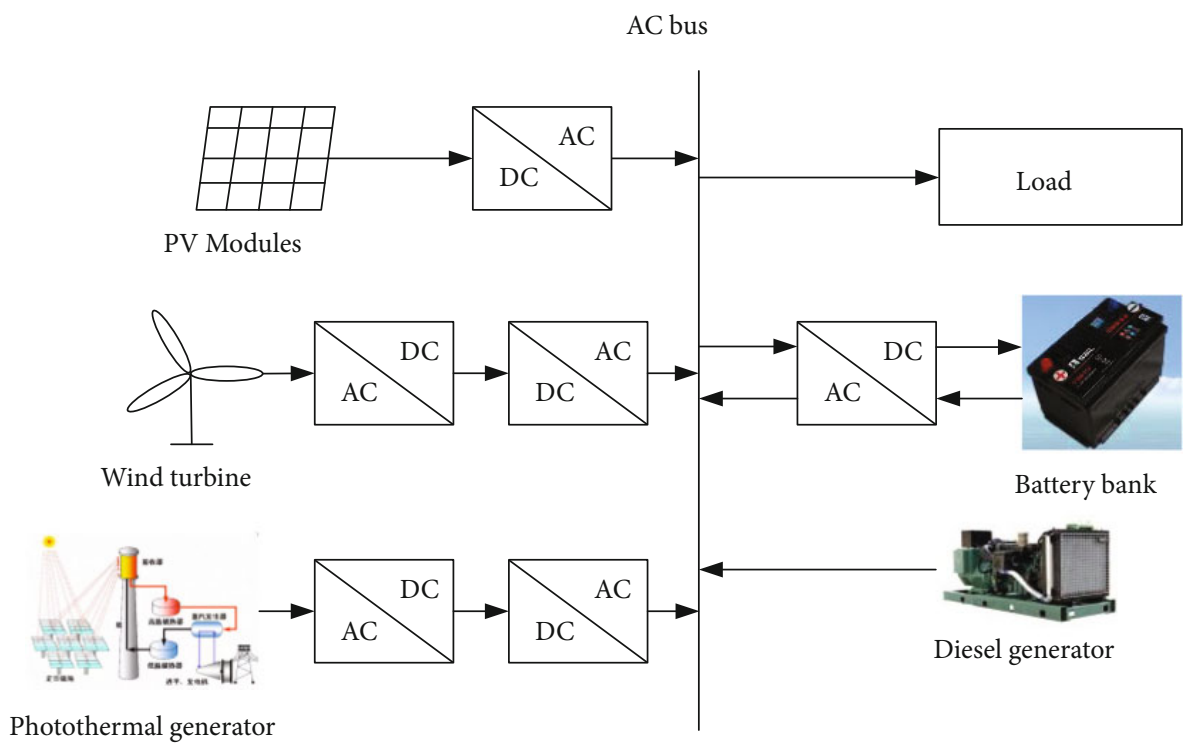

FIgURE 1: Microgrid topology.

\section{Modeling of Microgrid Components}

The microgrid topology is shown in Figure 1, which mainly includes photovoltaic, photothermal, wind, diesel generator, battery, and AC load [15].

2.1. PV Power Model. The actual output power of the photovoltaic cells is related to the solar irradiation and ambient temperature $[16,17]$. The actual output power of PV can be estimated as below:

$$
P_{\mathrm{PV}}(t)=\eta_{V} P_{T}\left[1+\rho_{V}\left(T_{r}+30 \eta_{V}-T_{T}\right)\right]
$$

where $P_{\mathrm{PV}}(\mathrm{kW})$ is the output power of a single PV panel. $P_{T}$ (W) denote the rated power of the PV module at standard test condition, and this paper takes $100 \mathrm{~W} . \eta_{V}$ is the ratio of real-time solar irradiation to solar irradiation under standard condition, and the standard solar irradiation is generally $1 \mathrm{~kW} / \mathrm{m}^{2} . \rho_{V}$ is the temperature coefficient, defined by $\left(-0.0047 /{ }^{\circ} \mathrm{C}\right) . T_{T}\left({ }^{\circ} \mathrm{C}\right)$ is the referenced ambient temperature, defined by $25^{\circ} \mathrm{C}$, and $T_{r}\left({ }^{\circ} \mathrm{C}\right)$ denotes the ambient temperature.

2.2. Wind Turbine Model. The output power of wind turbine is closely related to the wind speed, if the wind speed is too high or too low, it will affect the normal operation of the wind turbine $[18,19]$. The output power of wind turbine can be expressed as

$$
P_{W I}(t)=\left\{\begin{array}{l}
0, v<v_{c i}, v>v_{c o} \\
a v^{3}-b P_{r}, v_{c i}<v<v_{c o} \\
P_{r}, v_{r}<v<v_{c o}
\end{array}\right.
$$

where $a=\mathrm{P}_{\mathrm{r}} /\left(\mathrm{v}_{\mathrm{r}}^{3}-\mathrm{v}_{\mathrm{ci}}^{3}\right), b=\mathrm{v}_{\mathrm{ci}}^{3} /\left(\mathrm{v}_{\mathrm{r}}^{3}-\mathrm{v}_{\mathrm{ci}}^{3}\right) . P_{W I}(\mathrm{~kW})$ is the output power of single wind turbine. $v(\mathrm{~m} / \mathrm{s})$ is the wind speed. $P_{r}$ $(\mathrm{kW})$ is the rated power, defined by $10 \mathrm{~kW} . v_{\mathrm{ci}}(\mathrm{m} / \mathrm{s})$ and $v_{r}$ $(\mathrm{m} / \mathrm{s})$ are the cut-in wind speed and rated wind speed, respectively, defined by $2.5 \mathrm{~m} / \mathrm{s}$ and $12 \mathrm{~m} / \mathrm{s}$, respectively, and $v_{\text {co }}$ $(\mathrm{m} / \mathrm{s})$ is the cut-off wind speed, defined by $18 \mathrm{~m} / \mathrm{s}$.

2.3. PT Power Model. The effective power output by the heat absorber of the photothermal system is positively correlated with the area of the heliostats and solar irradiation [20-23]. The actual output power of the photothermal system can be expressed as follows:

$$
P_{\mathrm{PT}}(t)=P_{A P}(t)-\Delta P_{X}
$$

Among

$$
P_{A P}(t)=\operatorname{DNIS} \rho_{f} \rho_{c}(1-\xi),
$$

where $P_{P T}(\mathrm{~kW})$ is the output power of the single photothermal power system. $S\left(\mathrm{~m}^{2}\right)$ is the area of the heliostat, defined by $20 \mathrm{~m}^{2}$. DNI is the real-time solar irradiation. $\rho_{f}$ and $\rho_{c}$ are the plant efficiency and conversion efficiency of the heliostats, defined by 0.66 and 0.89 , respectively. $\xi$ is the reflectivity of the heat absorber surface, defined by $0.12 . P_{A P}(\mathrm{~kW})$ is the power reflected by the heliostat to the heat absorber surface, and $\Delta P_{X}(\mathrm{~kW})$ is the power loss of the heat absorber.

The power loss of the heat absorber is mainly reflected heat loss $P_{\text {ref }}$, specifically [24]

$$
\Delta P_{X}=P_{\text {ref }}=(1-\mathrm{a}) P_{A P}(t),
$$

where $\alpha$ is the absorptivity on the surface of absorber tube in the heat absorber, defined by 0.88 .

2.4. Diesel Generator Model. The actual output power of diesel generator set is related to the output power of a single diesel generator $[25,26]$, which is

$$
P_{\text {DG-total }}(t)=N_{\mathrm{DG}} P_{\mathrm{DG}}(t) \text {. }
$$


The real-time fuel consumption of the diesel generator is

$$
V_{f}(t)=\eta P_{D G-\text { total }}(t)
$$

where $P_{\mathrm{DG}-\text { total }}(\mathrm{kW})$ is the real-time total output power of the diesel generator set, and $P_{\mathrm{DG}}(\mathrm{kW})$ is the output power of a single diesel generator. $N_{\text {DG }}$ is the number of diesel generators. $V_{f}$ is the fuel consumption of diesel generator set. $\eta[\mathrm{L} /(\mathrm{kW} \cdot \mathrm{h})]$ is the fuel consumption rate of the diesel generator.

2.5. Energy Storage Model. The energy storage system is composed of battery packs. When the actual power generation is equal to the load demand, the energy storage system does not work; when the actual power generation is bigger than the load demand, the energy storage system charges; when the actual power generation is smaller than the load demand, the energy storage system discharges [27]. The charging and discharging expressions can be illustrated as follows:

Charging mode is as follows:

$$
C(t+1)=C(t)+P_{\mathrm{EL}} \xi_{\mathrm{EL}}
$$

Discharging mode is as follows:

$$
C(t+1)=C(t)-\frac{P_{\mathrm{RE}}}{x_{\mathrm{RE}}},
$$

where $C(t)$ is the power stored in the battery at time t. $P_{\mathrm{EL}}$ $(\mathrm{kW})$ is the charging power, and $P_{\mathrm{RE}}(\mathrm{kW})$ is the discharging power. $\xi_{\mathrm{EL}}$ is the charging efficiency, defined by $70 \%$, and $\xi_{\mathrm{RE}}$ is the discharging efficiency, defined by $90 \%$.

\section{The Power Allocation Strategy considering Thermal Storage System}

The photothermal power system is usually equipped with a thermal storage system, which can store excess energy by raising the temperature of the working medium to reduce the use of energy storage system [20]. Through actual investigation, the historical load curve of residents on the island can be obtained. Considering comprehensive economy cost, deficiency of power supply probability, and renewable energy discard rate, it is planned to adjust all renewable energy source first to meet the load demand of users, then the energy storage system, and finally the diesel generator in the actual operation process.

The difference power $P_{D}(t)$ was calculated between the total power generation of wind and photovoltaic and the residential load demand at time $t$, which is

$$
\mathrm{P}_{\mathrm{D}}(t)=\mathrm{N}_{\mathrm{PV}} \mathrm{P}_{P V}(t)+N_{\mathrm{WI}} \mathrm{P}_{\mathrm{WI}}(t)-\mathrm{P}_{\mathrm{IN}-\text { total }}(t),
$$

where $N_{\mathrm{PV}}$ and $N_{\mathrm{WI}}$ are the number of PV panel and wind turbine, respectively. $P_{\mathrm{IN}-\text { total }}(t)(\mathrm{kW})$ is the total residential load demand at time $t$.

The difference power $P_{D}(t)$ usually has the following two situations:
(1) $P_{D}(t)>0$, namely, the power generated by the photovoltaic and wind turbines meets the load demand, and the photothermal power generation system does not need to provide power. At this time, the photothermal power generation system stores the heat through the thermal storage system, and the stored energy is

$$
P_{\mathrm{TH}}(t)=N_{\mathrm{PT}} P_{\mathrm{PT}}(t),
$$

where $N_{\mathrm{PT}}$ is the number of the photothermal power system.

At this time, the difference power $P_{D}(t)$ is consumed by the energy storage system charging. The power stored by the energy storage system is

$$
\mathrm{P}_{\mathrm{EL}}(t)=\mathrm{P}_{\mathrm{D}}(t)
$$

If the energy storage system does not meet the charging conditions, $P_{D}(t)$ will be discarded by reducing the output of the renewable energy generators to match the load demand.

(2) $P_{D}(t)<0$, namely, the power generated by photovoltaic and wind turbines does not meet the load demand. The photothermal power generation system needs to provide additional power at this time

(a) If the power generation of the photothermal system is greater than the absolute value of the difference power $P_{D}(t)$, that is

$$
N_{\mathrm{PT}} P_{\mathrm{PT}}(t)>\left|P_{D}(t)\right|
$$

The load demand has been met. Then, the remaining heat energy of the photothermal power generation system is stored through the thermal storage system, and the stored energy is

$$
P_{\mathrm{TH}}(t)=N_{\mathrm{PT}} P_{\mathrm{PT}}(t)-\left|P_{D}(t)\right| \text {. }
$$

Neither the energy storage system nor the diesel generator is working at this time.

(b) If the power generation of the photothermal system is less than the absolute value of the difference power $P_{D}(t)$, that is

$$
N_{P T} P_{P T}(t)<\left|P_{D}(t)\right| \text {. }
$$

The load demand is still not met. Then, the energy storage system discharging or the diesel generator generating meets the load demand; that is,

$$
\left|P_{D}(t)\right|-N_{\mathrm{PT}} P_{\mathrm{PT}}(t)=N_{\mathrm{SE}} P_{\mathrm{RE}}(t)+N_{\mathrm{DG}} P_{\mathrm{DG}}(t)
$$

where $N_{\mathrm{SE}}$ is the number of battery packs. 
Specific to the power allocation of the energy storage system and the diesel generator, according to the converter rated capacity, SOC state, and discharging depth of batteries, the maximum power that can be discharged is determined first; then, the insufficient part will be supplemented by the diesel generator. The flow chart of power allocation strategy considering the thermal storage system is shown in Figure 2.

\section{Formulation of Optimization Problem}

\subsection{Objective Function}

(1) Comprehensive economic cost (CEC): it consists of the initial purchase costs, displacement costs, operational and maintenance costs, and fuel costs of all kinds of distributed power sources. The life span of photovoltaic, wind turbine, and photothermal is long; so, they only need to consider the initial purchase costs and operational and maintenance costs. This paper establishes the optimization goal with the lowest comprehensive economic cost, that is,

$$
\min C_{\text {total }}=\frac{\eta(1+\eta)^{y}}{(1+\eta)^{y}-1}\left(C_{p}+C_{r}\right)+C_{m}+C_{f}
$$

where $\eta$ denotes depreciation rate, defined by 5\%. $y$ denotes the system life span, defined by 20 years, typically equal to the life span of the PV panels, wind turbine, and photothermal. $C_{p}(¥), C_{r}(¥), C_{m}(¥)$, and $C_{f}(¥)$ are the total initial purchase cost, displacement cost, operational, and maintenance cost and fuel cost of the equipment in the microgrid, respectively.

The specific costs are shown in Equation (18):

$$
\begin{aligned}
\mathrm{C}_{\mathrm{p}}= & \mathrm{N}_{\mathrm{PV}} \mathrm{C}_{\mathrm{p}-\mathrm{PV}}+\mathrm{N}_{\mathrm{WI}} \mathrm{C}_{\mathrm{p}-\mathrm{WI}}+\mathrm{N}_{\mathrm{PT}} \mathrm{C}_{\mathrm{p}-\mathrm{PT}}+\mathrm{N}_{\mathrm{DG}} \mathrm{C}_{\mathrm{p}-\mathrm{DG}} \\
& +\mathrm{N}_{\mathrm{SE}} \mathrm{C}_{\mathrm{p}-\mathrm{SE}}, \\
\mathrm{C}_{\mathrm{r}}= & \mathrm{N}_{\mathrm{DG}} \mathrm{C}_{\mathrm{r}-\mathrm{DG}}+\mathrm{N}_{\mathrm{SE}} \mathrm{C}_{\mathrm{r}-\mathrm{SE}}, \\
\mathrm{C}_{\mathrm{m}}= & \mathrm{N}_{\mathrm{PV}} \mathrm{C}_{\mathrm{m}-\mathrm{PV}}+\mathrm{N}_{\mathrm{WI}} \mathrm{C}_{\mathrm{m}-\mathrm{WI}}+\mathrm{N}_{\mathrm{PT}} \mathrm{C}_{\mathrm{m}-\mathrm{PT}}+\mathrm{N}_{\mathrm{DG}} \mathrm{C}_{\mathrm{m}-\mathrm{DG}} \\
& +\mathrm{N}_{\mathrm{SE}} \mathrm{C}_{\mathrm{m}-\mathrm{SE}}, \\
\mathrm{C}_{\mathrm{f}}= & \int_{0}^{t} \mathrm{~N}_{\mathrm{DG}} C_{\mathrm{f}-\text { fuel }} V_{f}(t) d t,
\end{aligned}
$$

where $C_{p-\mathrm{PV}}, C_{p-\mathrm{WI}}, C_{p-\mathrm{PT}}, C_{p-\mathrm{DG}}$, and $C_{p-\mathrm{SE}}$ are, respectively, the initial purchase costs of photovoltaic, wind turbines, photothermal, diesel generators, and energy storage batteries. $C_{r-\mathrm{DG}}$ and $C_{r-\mathrm{SE}}$ are the displacement costs of diesel generators, and energy storage batteries, respectively. $C_{m-\mathrm{PV}}$, $C_{m-\mathrm{WI}}, C_{m-\mathrm{PT}}, C_{m-\mathrm{DG}}$, and $C_{m-\mathrm{SE}}$ are the operational and maintenance costs of photovoltaic, wind turbines, photother- mal, diesel generators, and energy storage batteries, respectively. $C_{f \text {-fuel }}(¥ / \mathrm{L})$ is the fuel unit price of a diesel generator.

(2) Deficiency of power supply probability (DPSP): it is an indicator to measure the power supply reliability. Namely the smaller the deficiency of power supply probability is, the higher the power supply reliability is. This paper establishes the optimization goal with the smallest of deficiency of power supply probability, that is,

$$
\min \text { DPSP }=\frac{\sum_{0}^{\mathrm{t}} \mathrm{P}_{\mathrm{def}}(t)}{\mathrm{P}_{\text {load }}}
$$

where $P_{\text {def }}(t)(\mathrm{kW})$ is the power shortage of the system at time $t . P_{\text {load }}(\mathrm{kW})$ is the total load power of the system.

(3) Renewable energy discard rate (REDR): the energy discard rate $\rho_{\text {REDR }}$ is used to measure the renewable energy utilization rate. Namely, the smaller the energy discard rate is, the higher the renewable energy utilization rate is. This paper establishes the optimization goal with the smallest of renewable energy discard rate, that is,

$$
\min \rho_{\mathrm{REDR}}=\frac{\sum_{0}^{\mathrm{t}} \mathrm{P}_{\mathrm{disc}}(t)}{\mathrm{P}_{\mathrm{re}}}
$$

where $P_{\text {disc }}(t)(\mathrm{kW})$ is the renewable energy generation discarded at time t. $P_{\text {re }}(\mathrm{kW})$ is the total renewable energy generation.

\subsection{Constraints}

(1) System power balance constraint: in order to meet the load demand, ensure stable operation of the system, and maintain the balance of input and output power of the microgrid, it is needed to meet

$$
\begin{aligned}
& N_{\mathrm{PV}} P_{\mathrm{PV}}(t)+N_{\mathrm{WI}} P_{\mathrm{WI}}(t)+N_{\mathrm{PT}} P_{\mathrm{PT}}(t)+N_{\mathrm{DG}} P_{\mathrm{DG}}(t)+N_{\mathrm{SE}} P_{\mathrm{RE}}(t) \\
& \quad=P_{\mathrm{IN}-\text { total }}(t)+N_{\mathrm{SE}} P_{\mathrm{EL}}(t) .
\end{aligned}
$$

(2) Operational constraint of the energy storage system: in order to improve the utilization rate of the battery pack and extend its life span, it needs to meet

$$
\mathrm{C}_{\min }(t+1) \leq \mathrm{C}(t+1) \leq \mathrm{C}_{\max }(t+1),
$$

where $C_{\max }(t+1)$ and $C_{\min }(t+1)$ being the maximum and minimum storage energies allowed, defined by $100 \%$ and $20 \%$, respectively. 


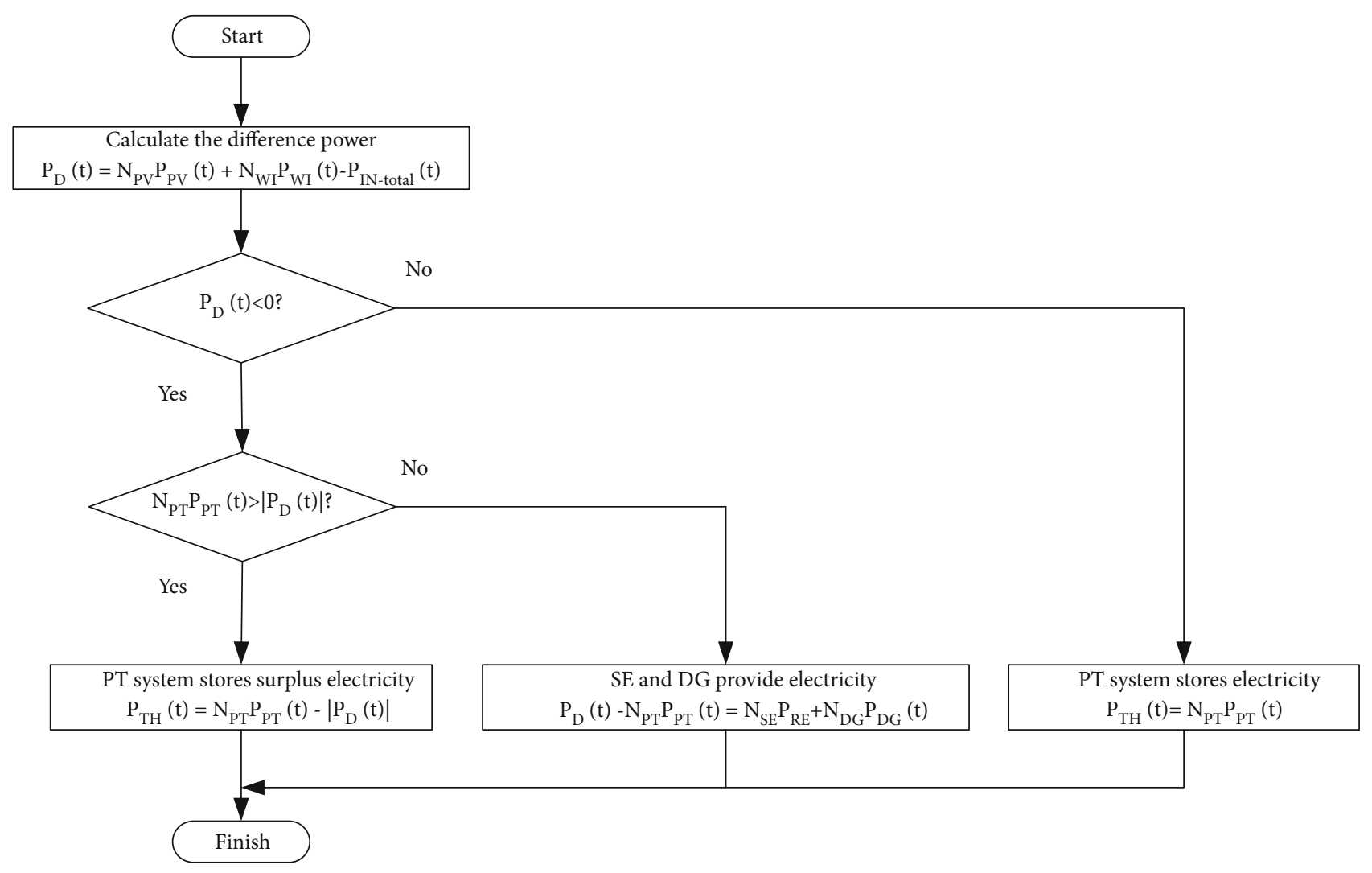

FIgURE 2: Flow chart of power allocation strategy.

(3) Constraint on the number of distributed power sources: according to actual engineering conditions, the number of power sources is restricted, and they need to meet

$$
\begin{aligned}
& 0 \leq \mathrm{N}_{\mathrm{PV}} \leq \mathrm{N}_{\mathrm{PV}-\text { max }}, \\
& 0 \leq \mathrm{N}_{\mathrm{WI}} \leq \mathrm{N}_{\mathrm{WI-max}}, \\
& 0 \leq \mathrm{N}_{\mathrm{PT}} \leq \mathrm{N}_{\mathrm{PT} \text {-max }}, \\
& 0 \leq \mathrm{N}_{\mathrm{DG}} \leq \mathrm{N}_{\mathrm{DG} \text {-max }}, \\
& 0 \leq \mathrm{N}_{\mathrm{SE}} \leq \mathrm{N}_{\mathrm{SE} \text {-max }},
\end{aligned}
$$

where $N_{\mathrm{PV}-\text { max }}, N_{\mathrm{WI}-\max }, N_{\mathrm{PT}-\text { max }}, N_{\mathrm{DG}-\text { max }}$, and $N_{\mathrm{SE}-\max }$ are the maximum allowable numbers of photovoltaic, wind, photothermal, diesel generators, and energy storage batteries, respectively.

(4) Operational constraint of diesel generator set: diesel generators have relatively low power generation efficiency and high fuel consumption during low-load operation, in order to optimize economy, and it is necessary to meet

$$
\mathrm{P}_{\mathrm{DG}-\min } \leq \mathrm{P}_{\mathrm{DG}}(t)<\mathrm{P}_{\mathrm{DG}-\max },
$$

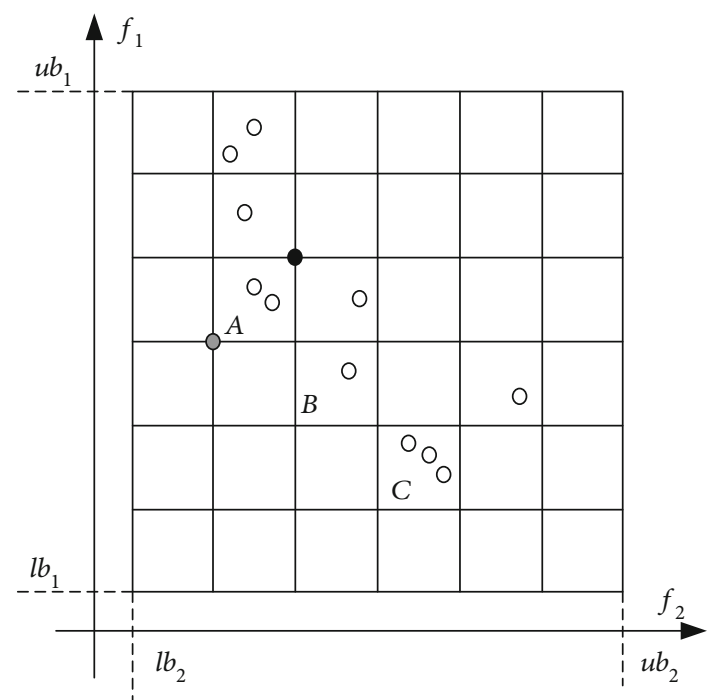

- Upper boundary point of region A

o Lower boundary point of region A

FIgURE 3: Grid and its boundaries.

where $P_{\mathrm{DG}-\max }$ and $P_{\mathrm{DG}-\min }$ are the upper limit and lower limit of the output power of a single diesel generator, respectively. 


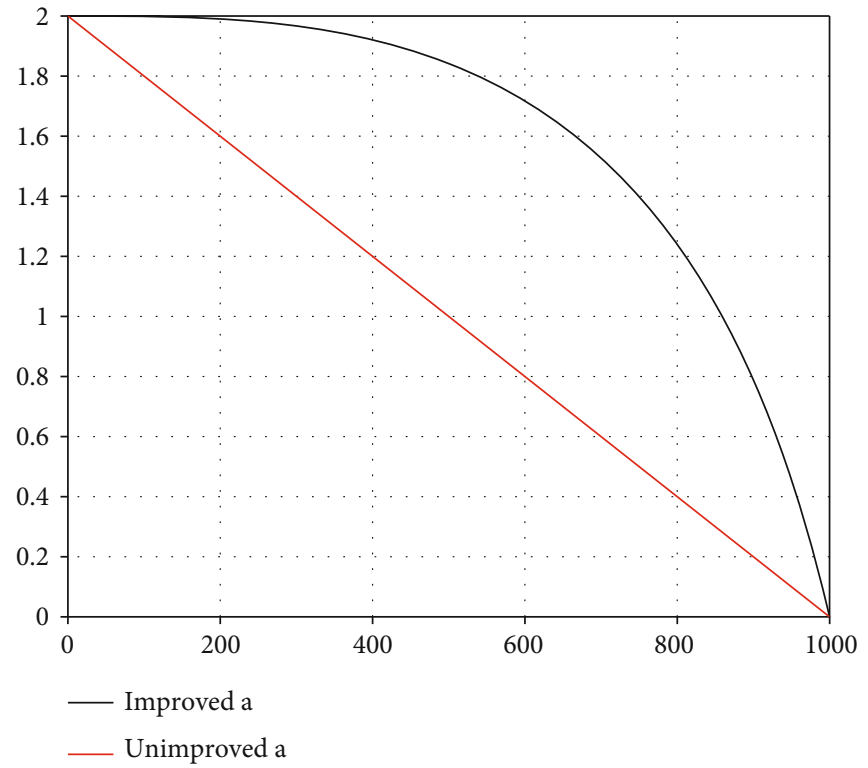

Figure 4: Convergence factor change curve.

\section{Improved Grey Wolf Optimizer}

5.1. Grey Wolf Optimizer. The Grey Wolf Optimizer (GWO) simulates the predation process of wolves with strict social dominant hierarchy in nature. The optimization search is achieved through processes such as "tracking," "encircling," "hunting," and "attacking" the prey [28]. It has been researched and applied in many fields because of its simple search principle, fast convergence speed, and good performance. However, the solution obtained by the GWO is gradually approaching the current optimal solution; so, the diversity of paretooptimal solution obtained is low. In the GWO, the current optimal three solutions are recorded as $\alpha$ wolf, $\beta$ wolf, and $\delta$ wolf, and other individual wolves hunt prey with the guidance of the three leader wolves. The main phases of grey wolf hunting are as follows:

$$
\begin{aligned}
\mathrm{D}_{\alpha, \beta, \delta} & =\left|\mathrm{CX}_{\mathrm{p}}(\mathrm{t})-\mathrm{X}_{\mathrm{j}}(\mathrm{t})\right|, \mathrm{p}=\alpha, \beta, \delta, \\
\mathrm{X}_{\mathrm{j}}(\mathrm{t}+1) & =\left(\left(\mathrm{X}_{\alpha}(\mathrm{t})-\mathrm{AD}_{\alpha}\right)+\left(\mathrm{X}_{\beta}(\mathrm{t})-\mathrm{AD}_{\beta}\right)+1 / 3\left(\mathrm{X}_{\delta}(\mathrm{t})-\mathrm{AD}_{\delta}\right)\right),
\end{aligned}
$$$$
\mathrm{C}=2 \mathrm{r}_{1} \text {, }
$$$$
\mathrm{A}=2 \mathrm{ar}_{2}-\mathrm{a} \text {, }
$$$$
\mathrm{a}=2-\frac{2 \mathrm{t}}{\text { Max_iter }},
$$

where $t$ indicates the current iteration. $X_{j}(t)$ is the position of $t$ th generation grey wolf individual, and $X_{p}(t)$ is the current position of prey. $r_{1}$ and $r_{2}$ are random numbers in [ll 1 l]. Max_iter is the maximum number of iterations, and $A$ and $C$ are swing factors.

5.2. Multiobjective Grey Wolf Optimization. In order to apply the GWO to the multiobjective optimization problems and make it a better performance, relevant researchers introduced the Archive (external population) into the GWO to store the nondominated optimal solution [29]. The leaders $\alpha$ wolves, $\beta$ wolves, and $\delta$ wolves in the predation process from the Archive are selected by adopting the leader wolves selection strategy. The algorithm can carry out jump search in space to increase the diversity of population by integrating differential evolution mechanism. The algorithm can also adapt to the multiobjective function in various situations to increase the flexibility of the algorithm by integrating greedy mechanism [30]. Thus, a multiobjective grey wolf optimization (MOGWO) is formed.

5.2.1. External Population and Leader Wolves Selection Strategy. Each iteration of the algorithm will generate new individuals. When individuals want to join the Archive, these individuals will be compared with the individuals in the Archive one by one, and then they can be added according to certain rules.

Stored all the nondominated optimal solutions in the Archive, the leader wolves are selected from the Archive by roulette [30]. In order to enhance the search performance of the GWO, the probability of any individual being selected can be calculated by equation (30):

$$
P_{j}=\frac{C}{N_{j}},
$$

where $C$ indicates a constant, whose value is greater than 1. $N_{j}$ is the total number of individuals in this individual's group.

5.2.2. Differential Evolution Mechanism. The differential evolution algorithm is improved from the genetic algorithm. The algorithm can carry out jump search in space to increase the diversity of population by using the individual difference 


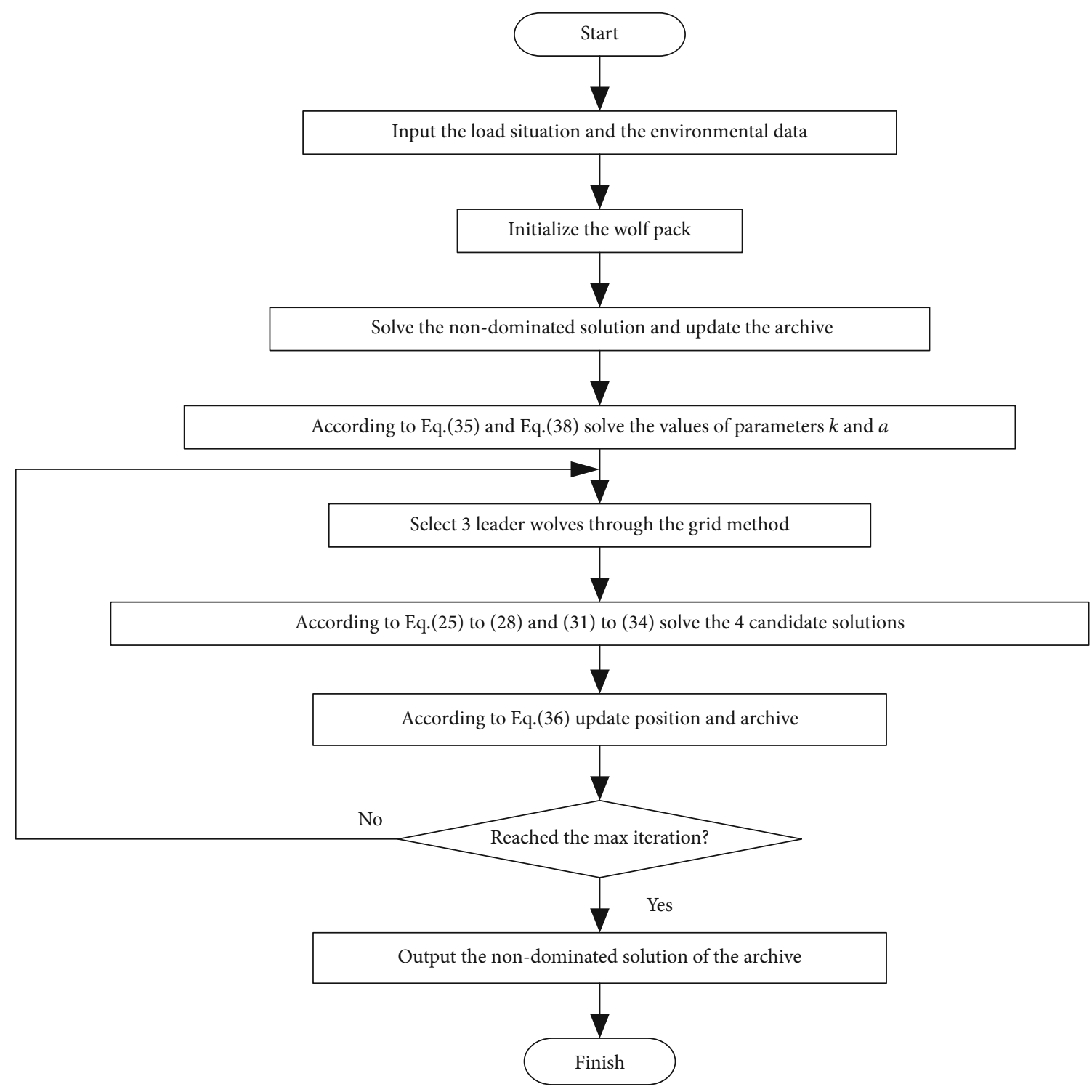

Figure 5: Algorithm optimization flow chart.

between the leader wolves. Because $\alpha, \beta$, and $\delta$ wolves are different wolves selected from the Archive, each leader wolf can be updated to obtain 3 positions that can be selected by individual wolves through the differential strategy plus the original solution generated by each $1 / 3$ weight, and the leader wolf can provide 4 candidate solutions, specific as follows:

$\mathrm{X}_{\mathrm{j} 1}(\mathrm{t}+1)=\mathrm{u}\left(\mathrm{X}_{\alpha}(\mathrm{t})-\mathrm{AD}_{\alpha}\right)+\mathrm{k}\left(\left(\mathrm{X}_{\beta}(\mathrm{t})-\mathrm{AD}_{\beta}\right)-\left(\mathrm{X}_{\delta}(\mathrm{t})-\mathrm{AD}_{\delta}\right)\right)$,

$\mathrm{X}_{\mathrm{j} 2}(\mathrm{t}+1)=\mathrm{u}\left(\mathrm{X}_{\beta}(\mathrm{t})-\mathrm{AD}_{\beta}\right)+\mathrm{k}\left(\left(\mathrm{X}_{\alpha}(\mathrm{t})-\mathrm{AD}_{\alpha}\right)-\left(\mathrm{X}_{\delta}(\mathrm{t})-\mathrm{AD}_{\delta}\right)\right)$,

$\mathrm{X}_{\mathrm{j} 3}(\mathrm{t}+1)=\mathrm{u}\left(\mathrm{X}_{\delta}(\mathrm{t})-\mathrm{AD}_{\delta}\right)+\mathrm{k}\left(\left(\mathrm{X}_{\alpha}(\mathrm{t})-\mathrm{AD}_{\alpha}\right)-\left(\mathrm{X}_{\beta}(\mathrm{t})-\mathrm{AD}_{\beta}\right)\right)$,
$\mathrm{X}_{\mathrm{j4}}(\mathrm{t}+1)=\frac{1}{3}\left(\left(\mathrm{X}_{\delta}(\mathrm{t})-\mathrm{AD}_{\delta}\right)+\left(\mathrm{X}_{\alpha}(\mathrm{t})-\mathrm{AD}_{\alpha}\right)+\left(\mathrm{X}_{\beta}(\mathrm{t})-\mathrm{AD}_{\beta}\right)\right)$,

where $u$ and $k$ are differential parameters.

The differential parameter $u$ reflects the dominance of different leader wolves, and its value is around $1 . k$ is the differential disturbance product factor, and the value range is [0 1 ], which is generally smaller than the parameter $u$. In order to balance global performance and local exploration ability, the differential parameter $k$ is dynamically adjusted according to individual wolf information, and the adjustment equation is as follows:

$$
\mathrm{k}=\mathrm{k}_{0}+\left(\mathrm{q}_{1}-\mathrm{q}_{2}\right) \frac{\mathrm{S}_{\mathrm{j} 1}-\left(\mathrm{S}_{\mathrm{j} 2}+\mathrm{S}_{\mathrm{j} 3} / 2\right)}{\mathrm{S}_{\mathrm{j} 4} *\left(\mathrm{~S}_{\mathrm{j} 2}+\mathrm{S}_{\mathrm{j} 3} / 2\right)}
$$




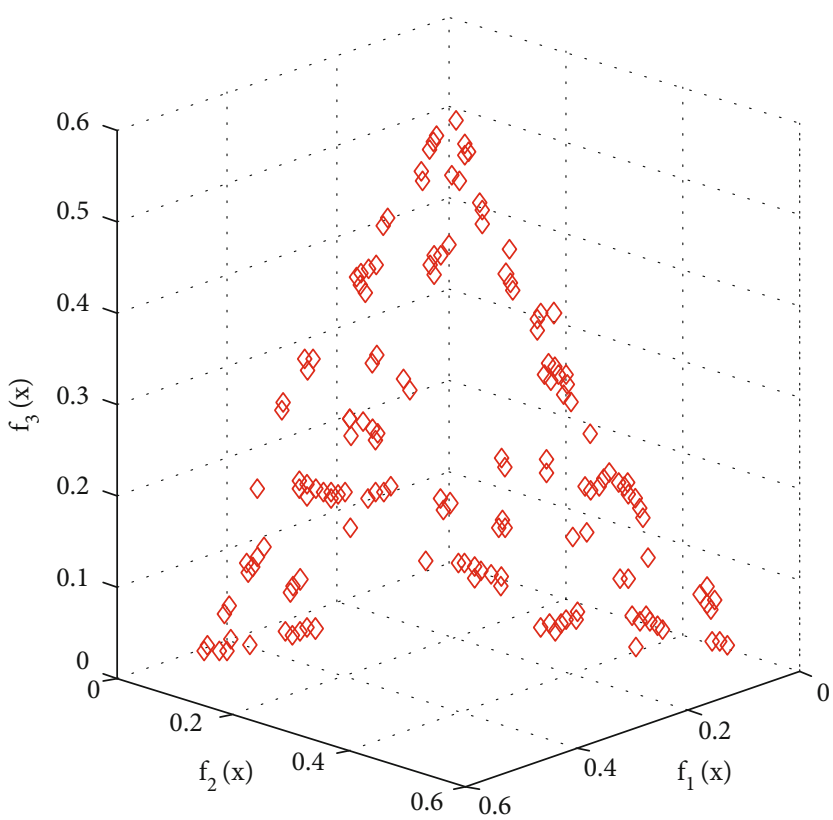

(a) DTLZ1 using NSGA-II

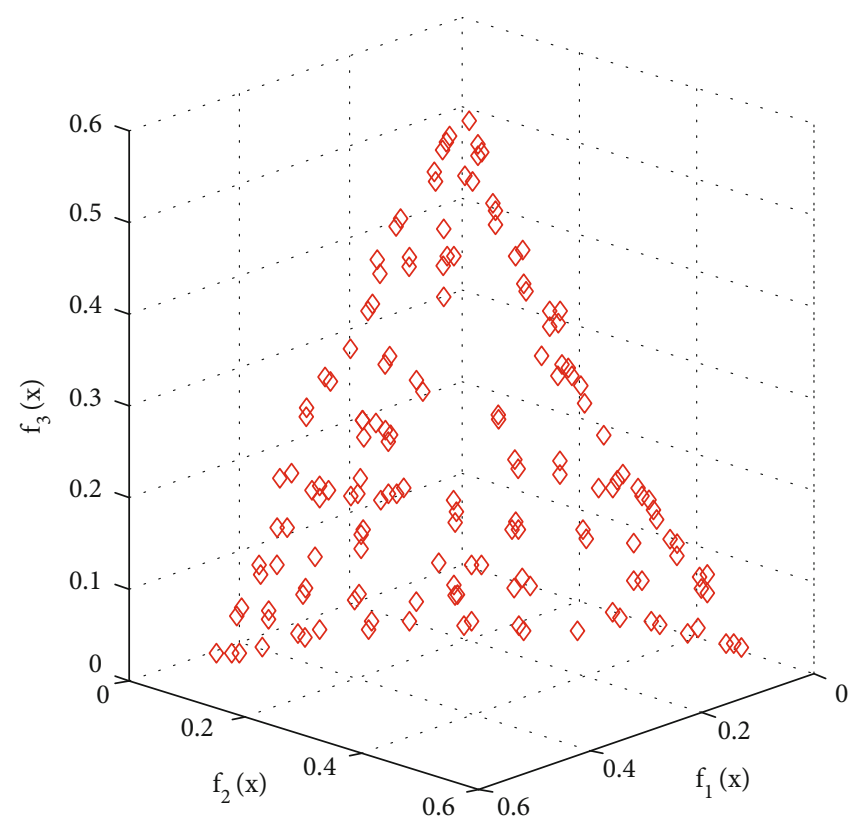

(b) DTLZ1 using MOGWO

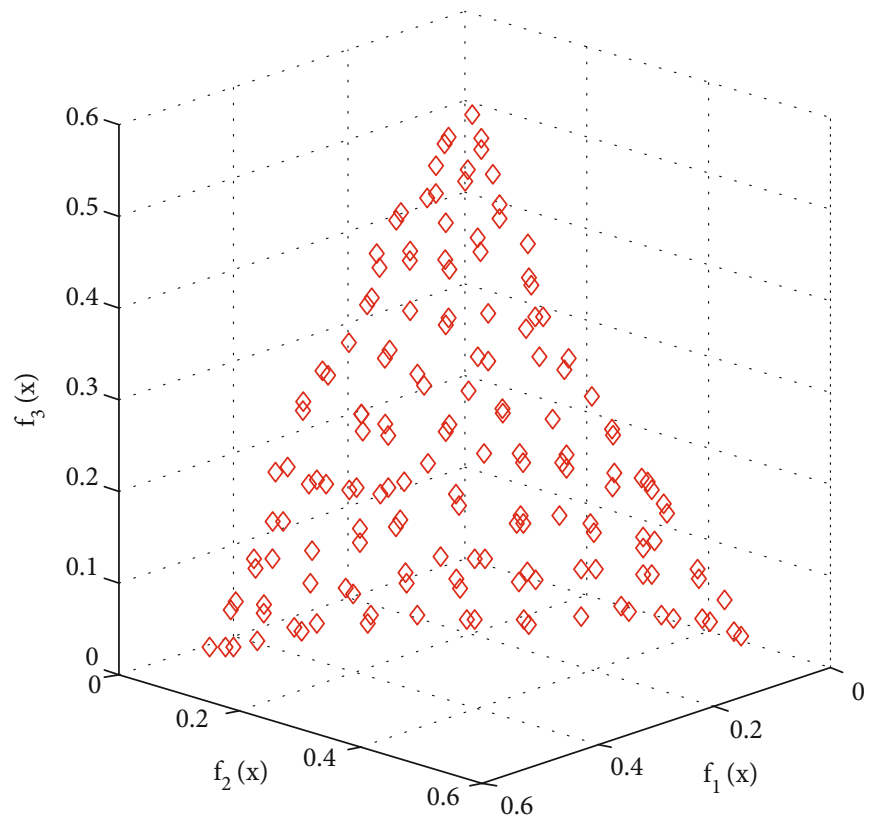

(c) DTLZ1 using IMOGWO

FIGURE 6: Paretofront obtained by solving DTLZ1 with 3 algorithms: (a) NSGA-II, (b) MOGWO, and (c) IMOGWO.

where $S_{j m}$ is the weighted sum of the objective function values of new position generated by the current individual, and after sorting, $S_{j 1}<S_{j 2}<S_{j 3}<S_{j 4}$. Parameter $k_{0}$ is the base value of $k$, and parameters $q_{1}$ and $q_{2}$ are the impact factors of $k_{0}$.

Equation (35) dynamically adjusts the parameter $k$ of differential evolution, if the current 4 individual differences are small, the larger the $k$ is; then, next time, the differential disturbance is increased, and the globality is strengthened to explore more solutions. Otherwise, if the differences are large, then the local precision development is carried out by reducing the differential disturbance.
5.2.3. Greedy Mechanism. Through equations (31) to (34), the individual wolves produce 4 candidate solutions, which are selected by the weighted summation of the nondominated solution and the objective function to ensure the excellent rate of the population. In addition, the original algorithm can adapt to multiple objective functions in different situations to increase the flexibility of the algorithm by introducing weight summation. Details are as follows:

(1) Find out the nondominant solution among the 4 solutions of individual wolf 


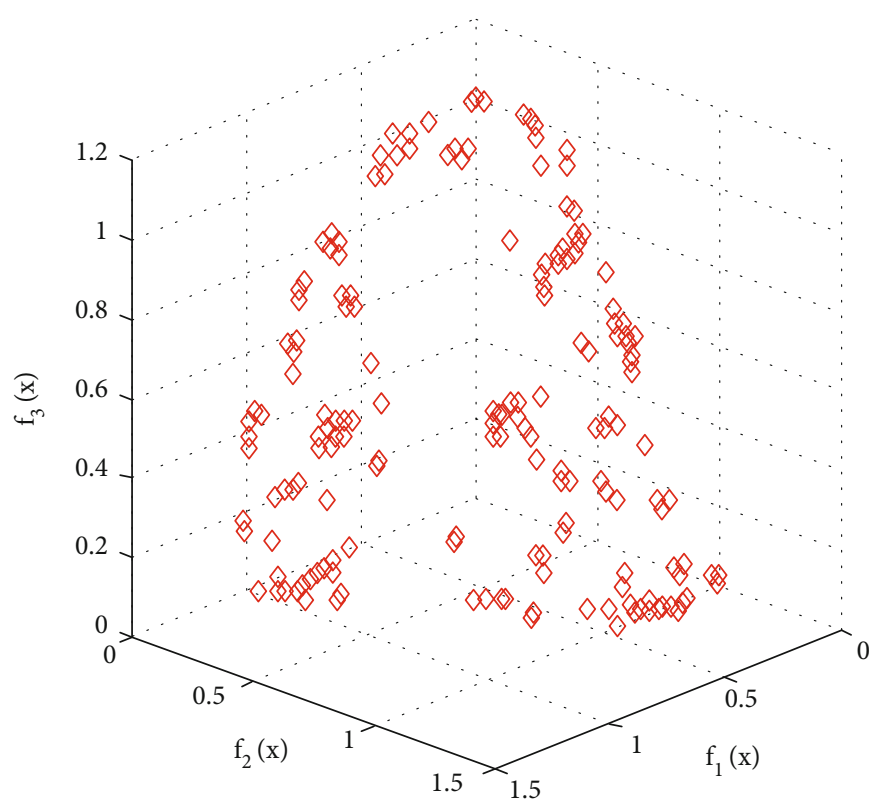

(a) DTZL2 using NSGA-II

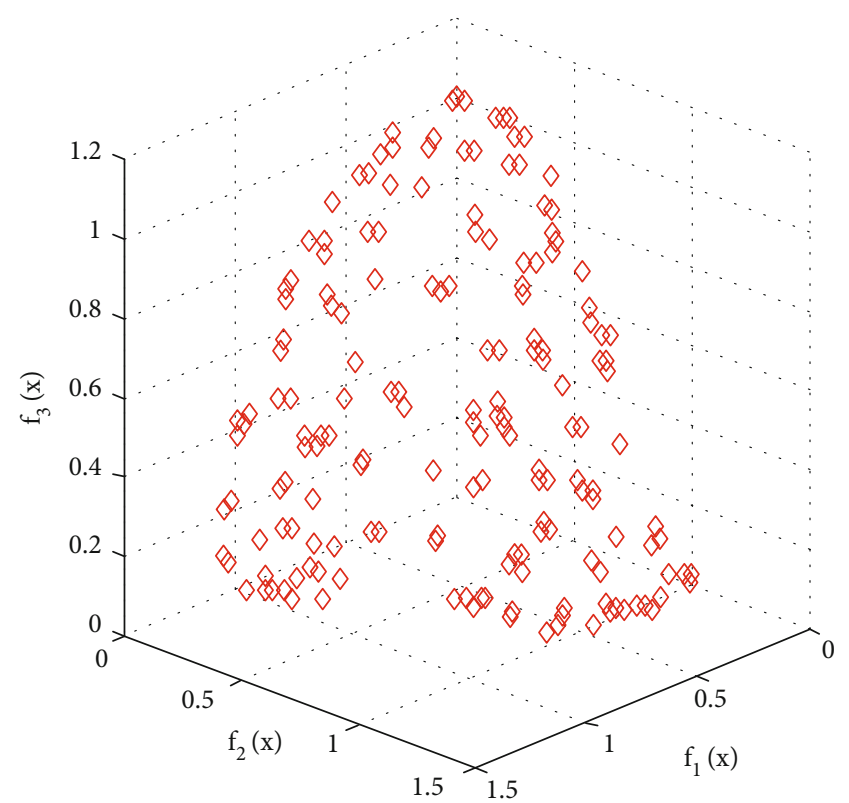

(b) DTZL2 using MOGWO

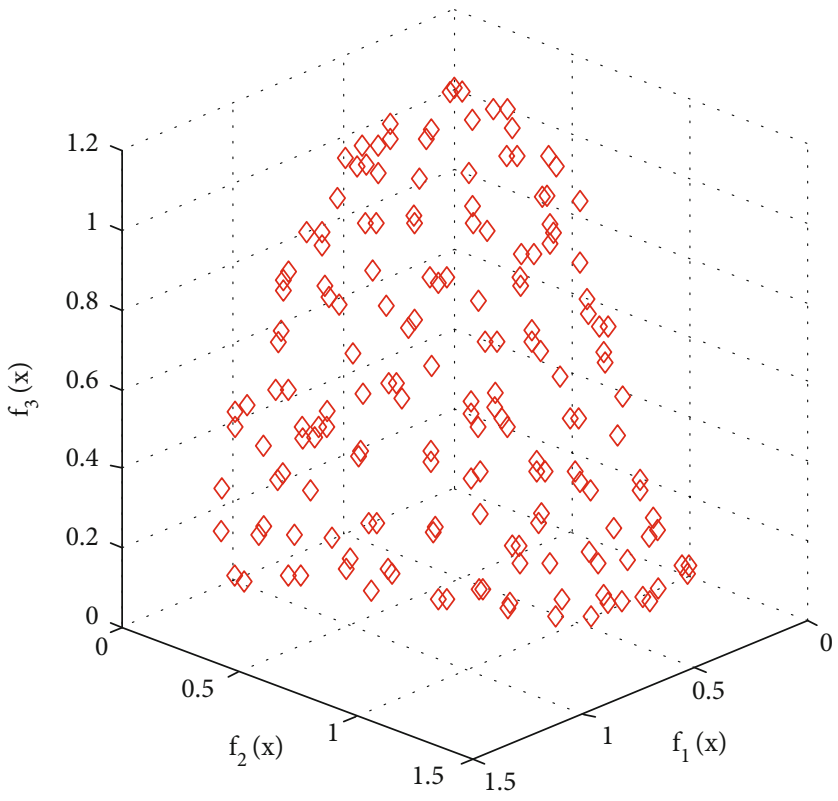

(c) DTZL2 using IMOGWO

FIGURE 7: Paretofront obtained by solving DTLZ2 with 3 algorithms: (a) NSGA-II, (b) MOGWO, and (c) IMOGWO.

TABLE 1: Comparison of performance indicators of 3 algorithms.

\begin{tabular}{|c|c|c|c|c|c|c|}
\hline \multirow{2}{*}{ Algorithm (problem) } & \multicolumn{2}{|c|}{ GD } & \multicolumn{2}{|c|}{$\mathrm{HV}$} & \multicolumn{2}{|c|}{$\Delta$} \\
\hline & Mean & Variance & Mean & Variance & Mean & Variance \\
\hline NSGA-II(DTLZ1) & 0.1947 & 0.1593 & 0.6873 & 0.0503 & 0.8596 & 0.0238 \\
\hline MOGWO(DTLZ1) & 0.0539 & 0.0398 & 0.7211 & 0.0551 & 0.7012 & 0.0162 \\
\hline IMOGWO(DTLZ1) & 0.0254 & 0.0512 & 0.7583 & 0.0422 & 0.5125 & 0.0089 \\
\hline NSGA-II(DTLZ2) & 0.2197 & 0.4364 & 0.6242 & 0.0754 & 0.9649 & 0.1332 \\
\hline MOGWO(DTLZ2) & 0.0215 & 0.0237 & 0.6754 & 0.0609 & 0.8797 & 0.2505 \\
\hline IMOGWO(DTLZ2) & 0.0182 & 0.0218 & 0.7005 & 0.0794 & 0.5014 & 0.0218 \\
\hline
\end{tabular}


TABLE 2: The relevant parameters of distributed power sources.

\begin{tabular}{|c|c|c|c|c|c|c|}
\hline Sources & $\begin{array}{c}\text { Rated } \\
\text { capacity } / \mathrm{kW}\end{array}$ & $\begin{array}{l}\text { Initial purchase } \\
\text { cost } /(¥ / \mathrm{kW})\end{array}$ & $\begin{array}{c}\text { Installed } \\
\text { cost } /(¥ / \mathrm{kW})\end{array}$ & $\begin{array}{c}\text { Operational and } \\
\text { maintenance cost } /(¥ / \mathrm{kW})\end{array}$ & Fuel cost/(¥/(kW·h)) & Lifespan/years \\
\hline $\mathrm{PV}$ & 0.1 & 5200 & 1500 & 14 & 0 & 20 \\
\hline WT & 80 & 2800 & 3200 & 6 & 0 & 20 \\
\hline $\mathrm{PT}$ & 100 & 5000 & 4000 & 5 & 0 & 20 \\
\hline DG & 60 & 300 & 570 & 27 & 1.45 & 10 \\
\hline BAT & $50(\mathrm{KW} \cdot \mathrm{h})$ & 1100 & 200 & 7 & 0 & 10 \\
\hline
\end{tabular}

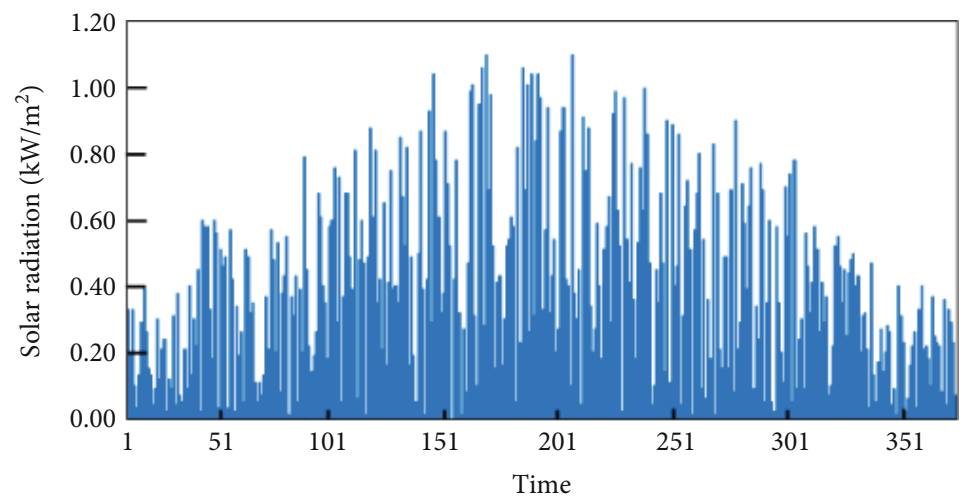

(a)

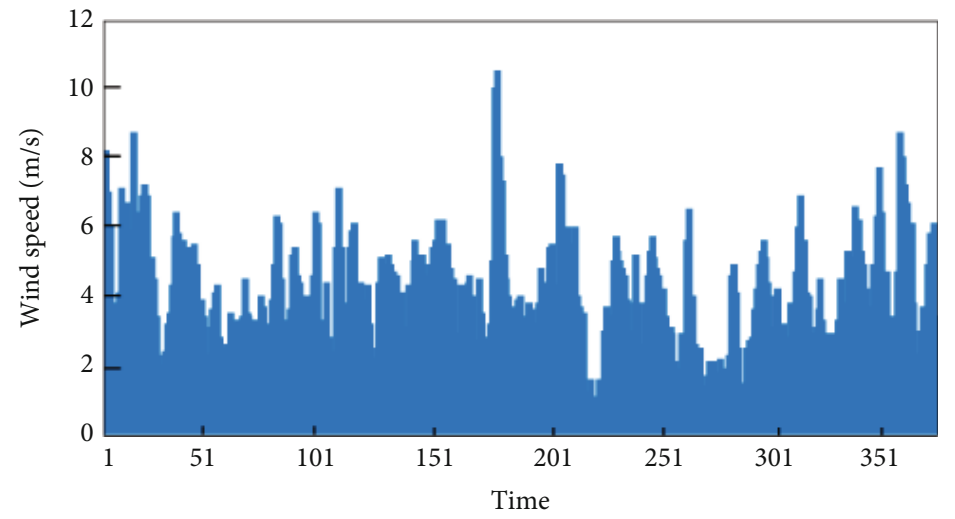

(b)

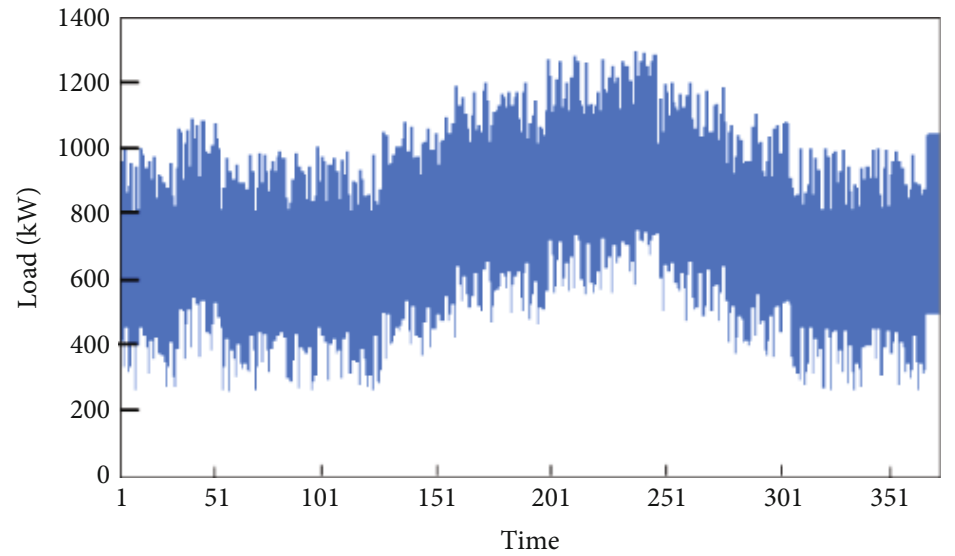

(c)

Figure 8: Environmental data and residential load curve. (a) Solar radiation curve. (b) Wind speed curve. (c) Residential load curve. 


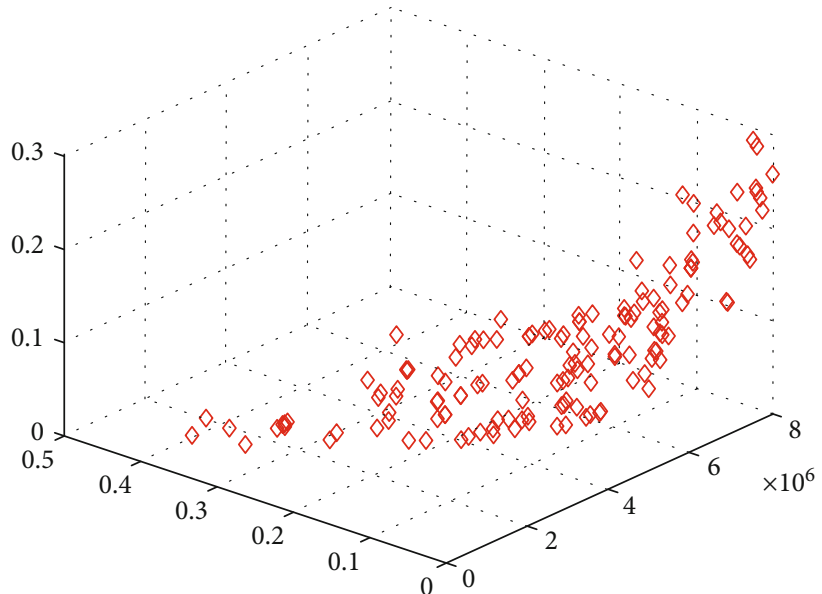

(a)

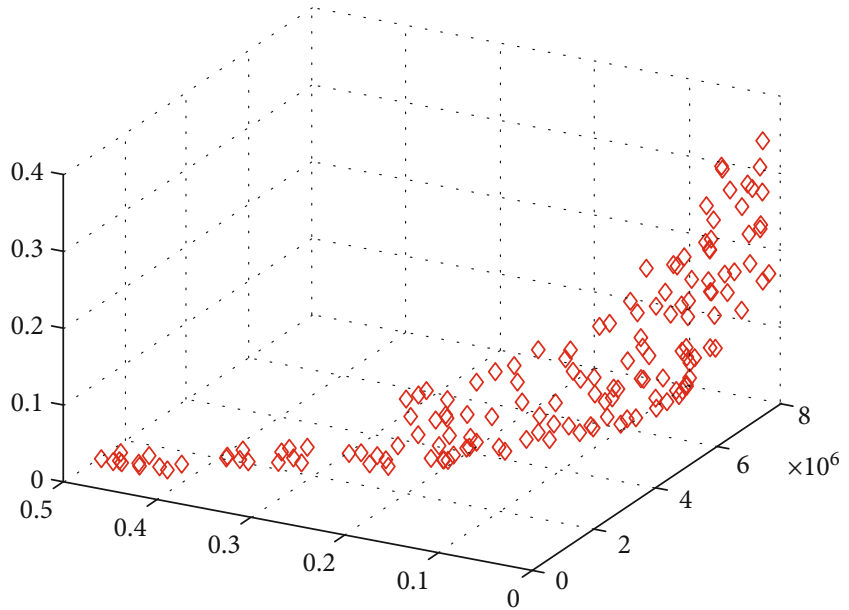

(b)

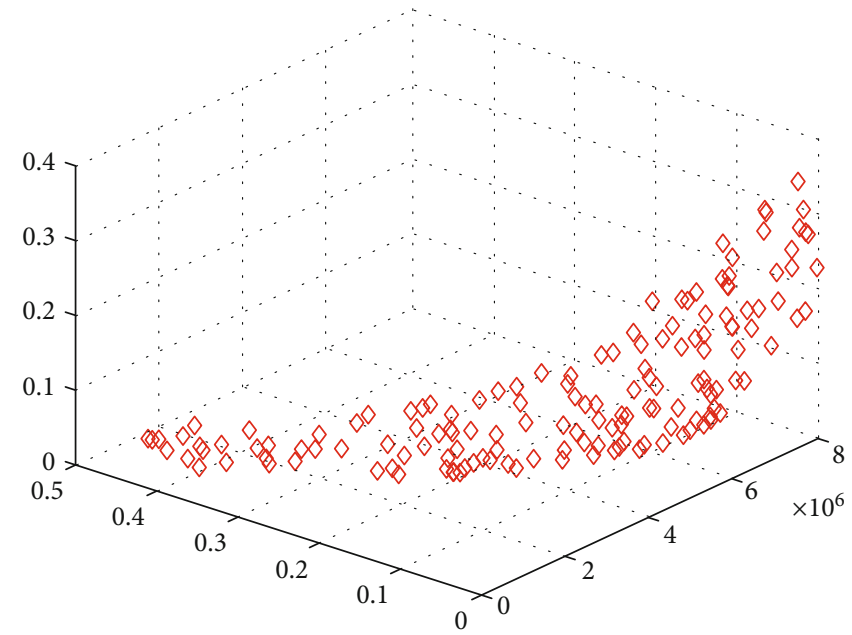

(c)

FIGURE 9: Paretooptimal fronts obtained by 3 algorithms. (a) NSGA-II optimization results. (b) MOGWO optimization results. (c) IMOGWO optimization results.

(2) If there are multiple nondominated solutions, the weighted summation of multiobjective function values is sorted:

$$
S_{j g}=\sum_{j=0}^{m} w_{j} f_{j}\left(x_{j g}\right), g=(1,2,3,4) \text {, }
$$

where $w$ and $j$ are weighted parameters, $\sum_{j=0}^{m} w_{j}=0$.

(3) The solution $x_{j g}$ with the smallest $S$ value is selected as the final update position of the current individual wolf

5.3. Improved Multiobjective Grey Wolf Optimization. In the MOGWO, there is a certain randomness to select the leader wolves by roulette, and it makes the algorithm easy to fall into local optimum. The convergence factor has the same rate of change in the whole iteration process, which will cause insufficient population diversity. Aiming at these weaknesses, this paper improves the leader wolves selection strategy and convergence factor to form an improved multiobjective grey wolf optimization (IMOGWO).

5.3.1. Improved Leader Wolves Selection Strategy. Stored all the nondominated optimal solutions in the Archive, there is a certain randomness to select the leader wolves by roulette. If the 3 leader wolves chosen are close to each other, the searching ability of the algorithm will be weakened and easily fall into the local optimum. In order to improve the exploration ability of the algorithm and make the population distribution more uniform, this paper use grid method to select leader wolves from the Archive (including $\alpha$ wolves, $\beta$ wolves, and $\delta$ wolves).

For an optimization problem with $r$ objectives, a grid with $2 r$ boundaries is set: lower bound $\left(\mathrm{lb}_{k}\right)$ and upper bound $\left(\mathrm{ub}_{k}\right)(k=1,2, \ldots, r)$. A grid can be divided into several small regions (called HC: hypercube), and the number of divisions is determined by the population size and the number of optimization objectives. Denote each HC as $r^{i}$, where $i=\left(i_{1}, i_{2}\right.$, 
TABLE 3: Distributed power supply configuration results of IMOGWO.

\begin{tabular}{lcccccccr}
\hline \multirow{2}{*}{ Schemes } & \multicolumn{9}{c}{ Number of distributed power sources } & CEC (10 $¥)$ & \multirow{2}{*}{ DPSP (\%) } \\
& PV & WT & PT & BAT & DG & REDR \\
\hline 1 & 14647 & 14 & 7 & 35 & 10 & 578.5106 & 0.255 \\
2 & 16398 & 17 & 8 & 52 & 10 & 723.2455 & 0.135 \\
3 & 15544 & 14 & 7 & 44 & 10 & 638.4003 & 0.1823 \\
4 & 16063 & 16 & 8 & 47 & 10 & 685.5224 & 0.159 \\
\hline
\end{tabular}

TABLE 4: Distributed power supply configuration results of MOGWO.

\begin{tabular}{lcccccccr}
\hline \multirow{2}{*}{ Schemes } & \multicolumn{9}{c}{ Number of distributed power sources } & CEC (10 $¥)$ & \multirow{2}{*}{ DPSP (\%) } \\
& PV & WT & PT & BAT & DG & REDR \\
\hline 1 & 17121 & 13 & 8 & 37 & 10 & 619.4335 & 0.268 & 0.191 \\
2 & 16924 & 16 & 9 & 51 & 10 & 728.3291 & 0.139 \\
3 & 15913 & 15 & 7 & 46 & 10 & 659.5921 & 0.212 \\
4 & 16707 & 15 & 8 & 43 & 10 & 662.4333 & 0.146 \\
\hline
\end{tabular}

TABLE 5: Distributed power supply configuration results of NSGA-II.

\begin{tabular}{|c|c|c|c|c|c|c|c|c|}
\hline \multirow{2}{*}{ Schemes } & \multicolumn{5}{|c|}{ Number of distributed power sources } & \multirow{2}{*}{ CEC (10 $\left.{ }^{4} ¥\right)$} & \multirow{2}{*}{ DPSP (\%) } & \multirow{2}{*}{ REDR } \\
\hline & PV & WT & $\mathrm{PT}$ & BAT & DG & & & \\
\hline 1 & 16908 & 15 & 8 & 39 & 10 & 642.3363 & 0.445 & 0.214 \\
\hline 2 & 16531 & 17 & 9 & 53 & 10 & 729.8754 & 0.153 & 0.271 \\
\hline 3 & 16341 & 14 & 8 & 45 & 10 & 664.0153 & 0.402 & 0.154 \\
\hline 4 & 16019 & 16 & 7 & 46 & 10 & 666.7994 & 0.291 & 0.206 \\
\hline
\end{tabular}

$\left.\cdots, i_{r}\right)$, and $i_{k} \in 1 . . d, d$ is a constant, representing the number of divisions in each dimension, which is generally a natural number greater than 2. In Figure 3, $d=6$. Then, the boundary of each $r^{i}$ can be expressed as

$$
\begin{gathered}
\forall k \in 1 . . r, \\
r \mathrm{ub} k, i=[\mathrm{lb} k+(i k / d)(\mathrm{ub} k-\mathrm{lb} k)] \cdot \omega k, \\
r \mathrm{lb} k, i=[\mathrm{lb} k+((i k-1) / d)(\mathrm{ub} k-\mathrm{lb} k)] \cdot \omega k,
\end{gathered}
$$

where $\omega_{k}$ is the width of each small region in the $k$ th dimension, $\omega_{k}=$ range $k / d$, and range $e_{k}$ is the field width in the $k$ th dimension.

With the grid and the identification of each small region in the grid, it can be judged whether an individual falls in a certain area. Suppose there is an individual $Z=\left(z_{1}, z_{2}, \cdots\right.$, $\left.z_{r}\right)$, for the area $r^{i}$, if $\forall k \in 1 \cdots r, z_{k} \geq r \mathrm{lb} k, i$, and $z_{k}<r u b k, i$ , then individual $Z$ is considered to be in region $r^{i}$.

The grey wolves in the Archive are ranked from high to low in terms of excellence, and the top 3 individual wolves are selected to judge whether there are individual wolves in the same grid. If there are, one or two of them will be removed, and then the fourth excellent individual is selected in the Archive to judge until the 3 individual wolves are in different grids; next, the 3 individual wolves are $\alpha$ wolf, $\beta$ wolf, and $\delta$ wolf, respectively.
In Figure 2, there are 2 individuals in region A, 1 individual in region $B$, and 3 individuals in region $C$. In order to maintain the uniform distribution of the evolutionary population, the individuals with high aggregation density in the grid should be deleted, such as deleting 1 individual in region $\mathrm{A}$ and 2 individuals in region $\mathrm{C}$.

5.3.2. Improved Convergence Factor. By equations (28) and (29), the value of $|A|$ is determined by the convergence factor $a$, and $a$ linearly decreases from 2 to 0 during the entire iteration. The convergence factor has the same rate of change in the whole iteration process, too fast convergence speed in the early stage of the iteration will lead to a smaller search range and insufficient population diversity, and too slow convergence speed in the later stage of the iteration will result in lower algorithm solving efficiency [29]. So, the convergence factor needs to be improved, that is,

$$
a=\frac{2}{\ln 3} * \ln \left(3-2\left(\frac{t}{\text { Max_iter }}\right)^{3}\right)
$$

Figure 4 shows the change curves of the 2 convergence factors. Through comparison, the use of nonlinear convergence factor in the early stage of the iteration has a slower decay rate, which can expand the global search range and 


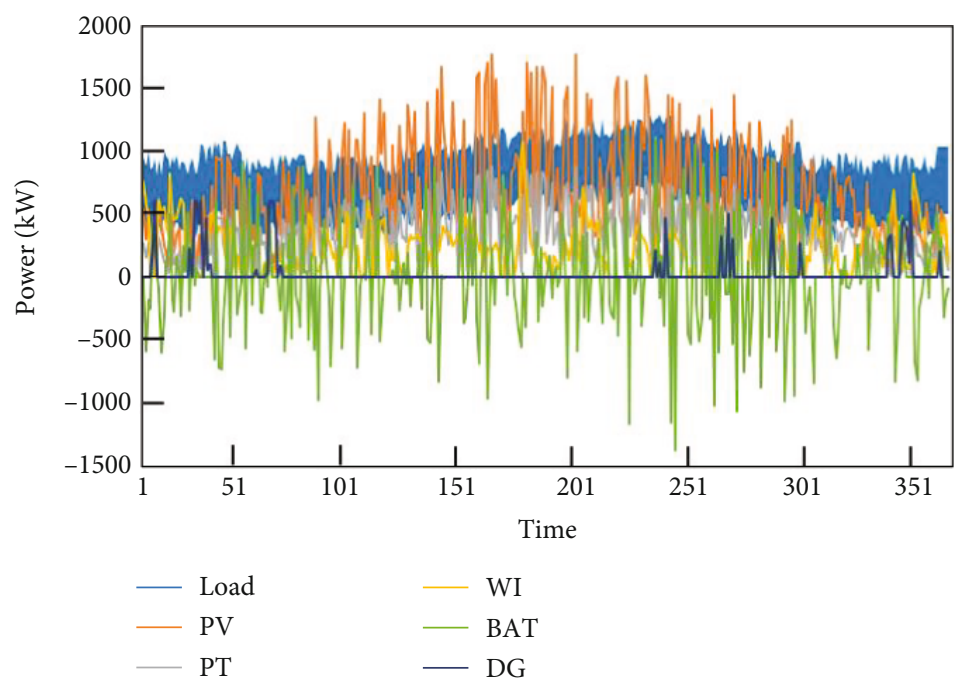

Figure 10: Annual distributed power output and load of microgrid.

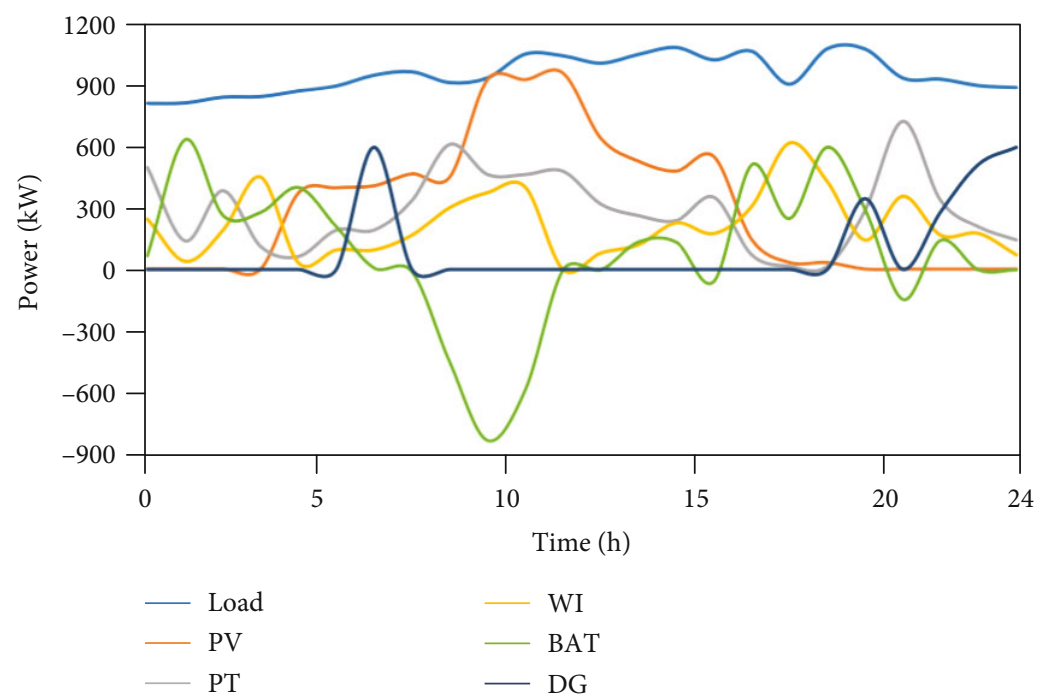

Figure 11: Typical daily distributed power supply output and load of microgrid.

ensure population diversity, and the faster decay rate in the later stage of the iteration can improve the solution efficiency to adapt to local development.

5.3.3. Algorithm Flow. The flowchart of solving the problem using the IMOGWO is shown in Figure 5, and the detailed optimization process is as follows:

(1) Input the load situation and the environmental data such as irradiation intensity, wind speed, temperature of the research site, and input the economic and technical parameters of each component of the research object

(2) Initialize the wolf pack, set the Archive, configure the algorithm parameters and differential parameters, and determine the maximum number of iterations Max_iter
(3) Solve the nondominated optimal solution of contemporary wolves and update the Archive

(4) According to equations (35) and (38), solve the values of the contemporary initialization parameters $k$ and $a$ and select 3 individual leader wolves from the Archive through the grid method

(5) According to equations (25)-(28) and (31)-(34), solve the 4 candidate solutions of the current individual leader wolves

(6) Solve the nondominant solutions among the candidate solutions, adopt the greedy mechanism and sort them according to equation (36), and select the best update position of each wolf

(7) According to the rules, add the nondominated solution to the Archive. If the population is full, remove part of the solutions in the Archive 


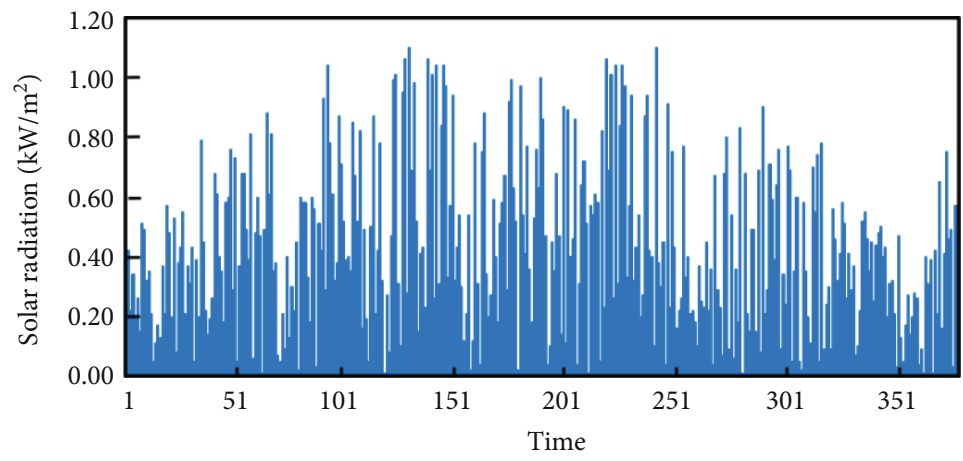

(a)

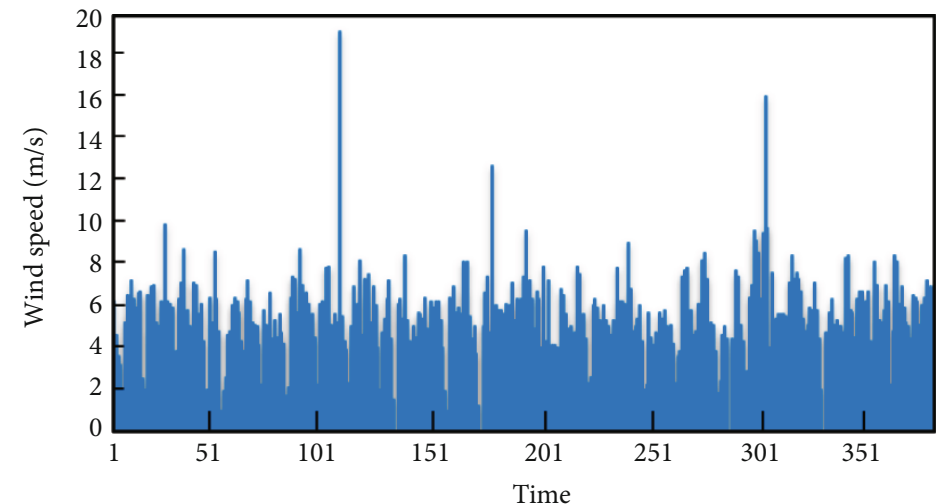

(b)

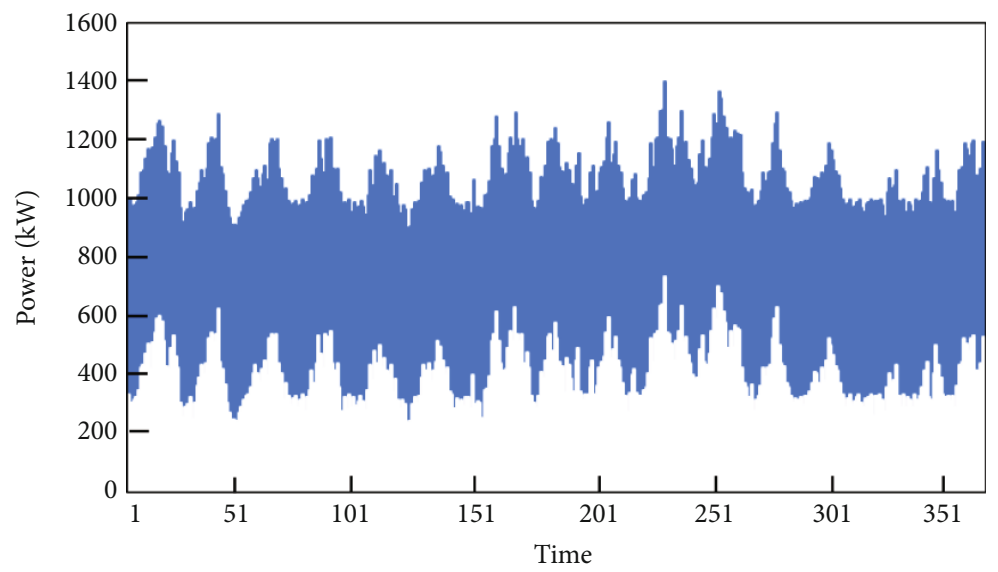

(c)

FIgURE 12: Environmental data and residential load curve. (a) Solar radiation curve. (b) Wind speed curve. (c) Residential load curve.

(8) Judge whether the maximum number of iterations has been reached, if so, the algorithm will end and output the nondominated solution of the Archive. Otherwise, return to step 4 and continue to execute the algorithm

5.3.4. Algorithm Performance Test. Standard multiobjective test functions DTLZ1 and DTLZ2 are used to test the performance of the IMOGWO and compared with the NSGA-II and the MOGWO. The generation distance (GD), hypervolume $(\mathrm{HV})$, and diversity $(\Delta)$ are selected as the performance indicators of the algorithm, and the convergence indicator and diversity indicator are used to evaluate the results of the algorithm.
Test functions are as follows:

(1) DTLZ1:

$$
\left\{\begin{array}{l}
\min f_{1}(x)=0.5 x_{1} x_{2}(1+g(x)), \\
\min f_{2}(x)=0.5 x_{1}\left(1-x_{2}\right)(1+g(x)), \\
\min f_{3}(x)=0.5\left(1-x_{1}\right)(1+g(x)), \\
g(x)=\sum_{i=3}^{12}\left(x_{i}-0.5\right)^{2}-\cos \left(20 p\left(x_{i}-0.5\right)\right), \\
\text { S.T. } \quad 0 £ x_{i} £ 1 \quad(i=1,2, \cdots, 12) .
\end{array}\right.
$$


Paretooptimal boundary corresponds to $X$ that is $x_{i}=0$, $x_{i} \in X_{M}$.

(2) DTLZ2:

$$
\left\{\begin{array}{l}
\min f_{1}(x)=(1+g(x)) \cos \left(x_{1} \pi / 2\right) \cos \left(x_{2} \pi / 2\right), \\
\min f_{2}(x)=(1+g(x)) \cos \left(x_{1} \pi / 2\right) \sin \left(x_{2} \pi / 2\right), \\
\min f_{3}(x)=(1+g(x)) \sin \left(x_{1} \pi / 2\right), \\
g(x)=\sum_{i=3}^{12}\left(x_{i}-0.5\right)^{2}, \\
\text { S.T. } \quad 0 \leq x_{i} \leq 1 \quad(i=1,2, \cdots, 12) .
\end{array}\right.
$$

Paretooptimal boundary corresponds to $\mathrm{X}$ is: $x_{i}=0, x_{i}$ $\in X_{M}$.

Algorithm parameters are coded by real number system and polynomial variation. The NSGA-II uses analog binary crossover operator. Population size is 200, maximum number of iterations is 500 , crossover probability is 0.9 , mutation probability is $1 /$ len, len is variable dimension, and the size of the Archive is 150 . The paretofront of the obtained nondominated solution is shown in Figures 6 and 7.

It can be seen from Figures 6 and 7 that all three algorithms can find nondominated solutions and obtain the paretofront. Compared with the other 2 algorithms, the optimal solution obtained by IMOGWO is distributed more uniformly on paretofront, and local convergence of the algorithm can be avoided.

The quantitative analysis results of the performance of the three algorithms are shown in Table 1.

It can be seen from Table 1 that the IMOGWO is superior to the MOGWO and NSGA-II in both the generation distance and the hypervolume indicator, which verifies the superiority of the IMOGWO in solving the three-objective optimization problem.

The IMOGWO can expand the search scope in the early iteration to enhance the diversity of the grey wolf population, while in the late iteration, it can realize rapid convergence to enhance the solving efficiency of the algorithm. In addition, the IMOGWO also has a good improvement in the convergence and coverage [30].

\section{Case Study}

6.1. Case Situation. An isolated microgrid project in a certain place in China (The geographical coordinates are $18^{\circ} 10^{\prime} \mathrm{N}$ and $108^{\circ} 57^{\prime} \mathrm{E}$ ) is selected as the research object. The simulation analysis of optimal sizing is carried out according to the annual forecast of environmental conditions and load demand in the area. Table 2 shows the relevant parameters of distributed power sources. And Figure 8 shows the weather data and common loads of the place in a certain year. The weather data comes from the China Greenhouse Data Sharing Platform [31].

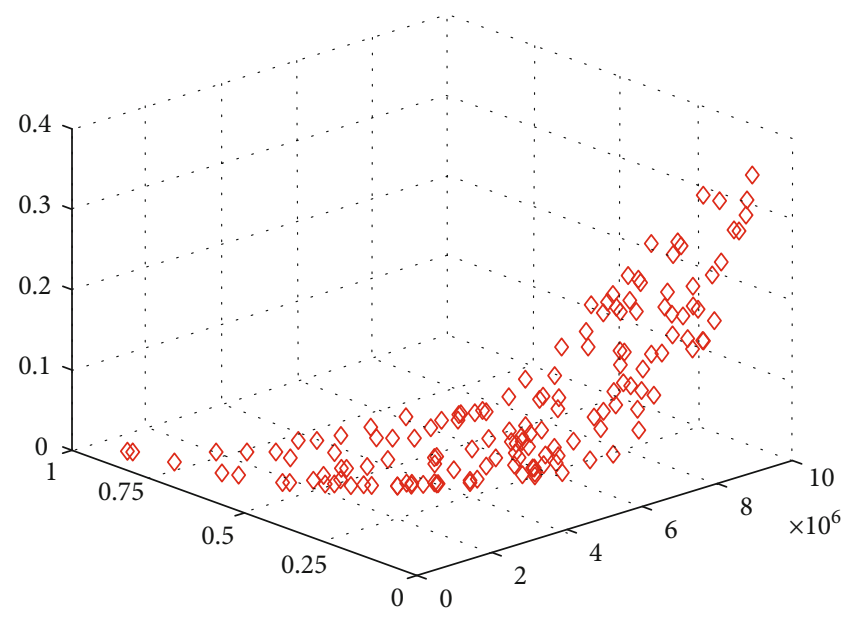

Figure 13: Paretooptimal fronts obtained by IMOGWO.

6.2. Case Analysis 1. According to the known conditions in 5.1, a three-objective optimization model based on comprehensive economic cost, deficiency of power supply probability, and renewable energy discard rate is established. In this paper, the diesel generator does not participate in the optimal configuration of system capacity, and its capacity is set at $60 \%$ of the average annual load as the backup power source of the system. Set the population size to 200, the maximum number of iterations to 500, and the Archive size to 150 . The three-objective optimization model proposed is solved by using the NSGA-II, the MOGWO, and the IMOGWO, respectively. The paretooptimal fronts obtained are shown in Figure 9.

It can be seen from Figure 8 that all 3 algorithms can find the nondominated solutions and obtain paretofronts. However, the distribution and convergence of the NSGA-II are the worst, which is not suitable to solve the three-objective optimization problem established in this paper. The MOGWO and the IMOGWO can obtain more ideal optimization results, and the IMOGWO has a significant improvement in the uniformity of the paretofront distribution compared with the MOGWO.

Among the nondominated solutions that meet all goals, four representative solutions are selected with the lowest comprehensive economic cost, the smallest DPSP, the smallest REDR, and the compromise between the 3 goals. The optimal configuration schemes corresponding to IMOGWO, MOGWO, and NSGA-II are shown in Tables 3-5, respectively.

It can be seen from Table 3 that the minimum comprehensive economic cost of the system is RMB 5.785106 million, the corresponding deficiency of power supply probability is $0.255 \%$, and the renewable energy discard rate is 0.185 . The maximum comprehensive economic cost of the system is RMB 7.232455 million, the corresponding deficiency of power supply probability is $0.135 \%$, and the renewable energy discard rate is 0.184 . The comprehensive economic cost of the system is RMB 6.384403 million, the corresponding deficiency of power supply probability is $0.423 \%$, and the renewable energy discard rate is 0.133 . It can be seen from Table 4 that the minimum comprehensive 
TABLE 6: Distributed power supply configuration results of IMOGWO.

\begin{tabular}{|c|c|c|c|c|c|c|c|c|}
\hline \multirow{2}{*}{ Schemes } & \multicolumn{5}{|c|}{ Number of distributed power sources } & \multirow{2}{*}{$\operatorname{CEC}\left(10^{4} ¥\right)$} & \multirow{2}{*}{ DPSP (\%) } & \multirow{2}{*}{ REDR } \\
\hline & PV & WT & PT & BAT & DG & & & \\
\hline 1 & 14267 & 18 & 8 & 39 & 10 & 636.0827 & 0.186 & 0.248 \\
\hline
\end{tabular}

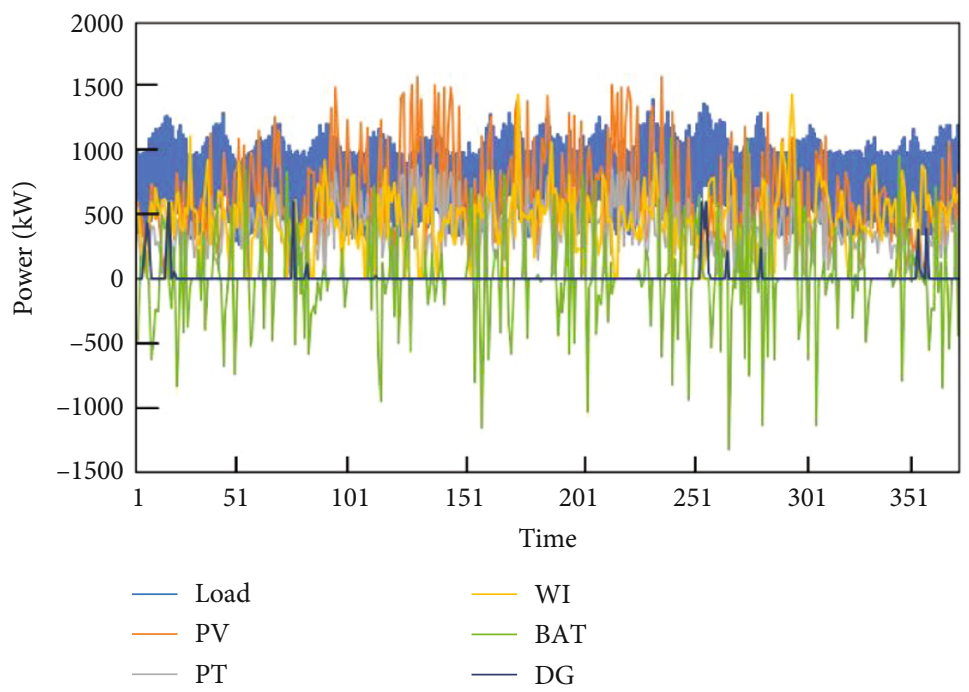

Figure 14: Annual distributed power output and load of microgrid.

economic cost of the system is RMB 6.194335 million, the corresponding deficiency of power supply probability is $0.268 \%$, and the renewable energy discard rate is 0.191 . The maximum comprehensive economic cost of the system is RMB 7.283291 million, the corresponding deficiency of power supply probability is $0.144 \%$, and the renewable energy discard rate is 0.212 . The comprehensive economic cost of the system is RMB 6.595921 million, the corresponding deficiency of power supply probability is $0.382 \%$, and the renewable energy discard rate is 0.146 . It can be seen from Table 5 that the minimum comprehensive economic cost of the system is RMB 6.423363 million, the corresponding deficiency of power supply probability is $0.445 \%$, and the renewable energy discard rate is 0.214 . The maximum comprehensive economic cost of the system is RMB 7.298754 million, the corresponding deficiency of power supply probability is $0.153 \%$, and the renewable energy discard rate is 0.271 . The comprehensive economic cost of the system is RMB 6.640153 million, the corresponding deficiency of power supply probability is $0.402 \%$, and the renewable energy discard rate is 0.154 . From the above, when the renewable energy discard rate is similar, the higher the comprehensive economic cost of system is, the lower the deficiency of power supply probability is, namely, the higher the power supply reliability is, which means that under general circumstances, high power supply reliability will come at the high comprehensive economy cost. When the comprehensive economic cost is similar, the smaller the deficiency of power supply probability is, the higher the corresponding renewable energy discard rate is. Therefore, in the overall planning of the microgrid, it is necessary to appropriately evaluate and balance the relationship between comprehensive economic cost, deficiency of power supply probability, and renewable energy discard rate according to the actual requirements of the planning object, and appropriate values for the three are determined to avoid excessive costs.

According to Tables 3-5, compared with NSGA-II, the optimal sizing obtained by IMOGWO and MOGWO is more excellent. Taking scheme 4 as an example, compared with MOGWO, although the comprehensive economy cost of IMOGWO is higher than that of MOGWO, the DPSP and the REDR are lower than that of MOGWO. Therefore, the final choice depends on the requirements of local residents and power enterprises.

This paper selects a set of solutions in scheme 4 in Table 3 for further analysis. The components that constitute the hybrid energy microgrid in this solution include 16,063 photovoltaic cell panels, 16 wind generators, 8 photothermal generators, 47 battery packs, and 10 diesel generators.

Figure 10 shows the annual operational condition of each distributed power source, battery packs and load in the microgrid, and Figure 11 shows the typical daily power output and load operational condition of the microgrid. It can be seen from the figure that the power output of photovoltaic generator, photothermal generators, and wind generators is relatively random, but they can also form a relatively good complementarity. Through the blessing of energy storage batteries and diesel generators, they can provide energy when renewable energy generating capacity is insufficient, which can effectively improve the stability of the microgrid system. 


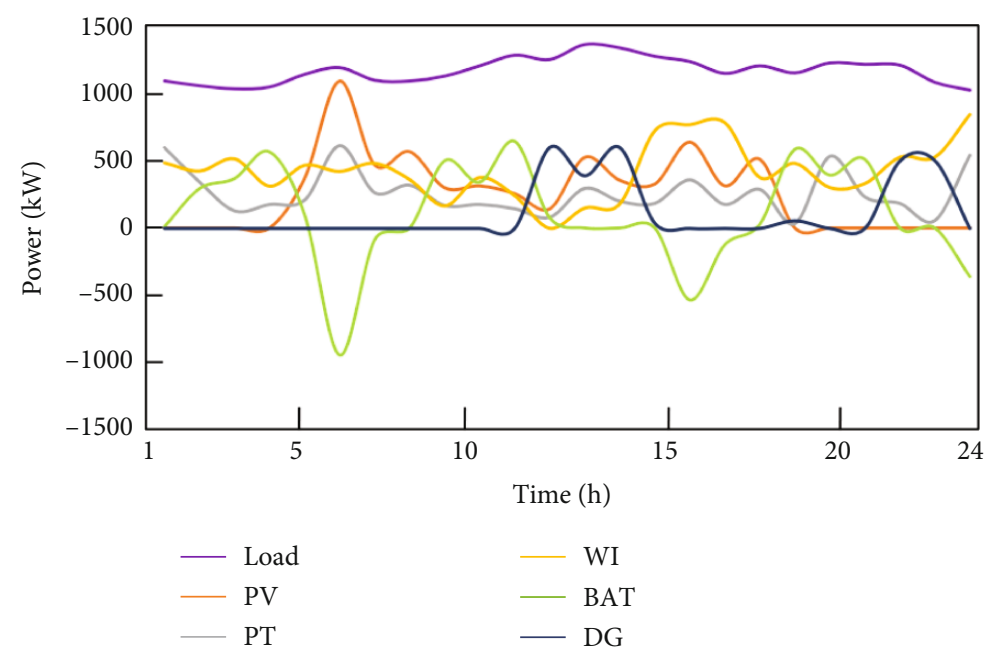

FIGURE 15: Typical daily distributed power supply output and load of microgrid.

Through the analysis of the operating conditions, it is verified that the IMOGWO is feasible to solve the sizing optimization problem of microgrid.

6.3. Case Analysis 2. An isolated microgrid project in a certain place in China (The geographical coordinates are $36^{\circ} 10^{\prime} \mathrm{N}$ and $120^{\circ} 10^{\prime} \mathrm{E}$ ) is selected as the research object. The simulation analysis of optimal sizing is carried out according to the annual forecast of environmental conditions and load demand in the area. Figure 12 shows the weather data and common loads of the place in a certain year. The weather data comes from the China Greenhouse Data Sharing Platform [31].

With the same conditions as in 6.2, the three-objective optimization model proposed is solved by using the IMOGWO, and the paretooptimal fronts obtained are shown in Figure 13. A set of solution is obtained as shown in Table 6, and this set of solution is used for further analysis.

Figure 14 shows the annual operational condition of each distributed power source, battery packs, and load in the microgrid, and Figure 15 shows the typical daily power output and load operational condition of the microgrid. As can be seen from the above two figures, the optimal sizing obtained by this optimization method can meet the load demand of this region and has low DPSP and REDR.

\section{Conclusions}

Based on the comprehensive consideration of load demand, wind speed, and solar radiation, a three-objective optimal sizing model and its solution method are proposed for the island microgrid containing photovoltaic/photothermal/wind/diesel/storage. The system power allocation strategy is proposed considering the three types of controllable resources for thermal storage module of the photothermal power generation system, battery, and diesel generator. The rationality of the proposed model and power allocation strategy is verified by modelling and solving analysis of actual example of island in a certain area. At the same time, this paper proposes an IMOGWO to solve the three-objective optimization problem, and simulation analysis verified that the IMOGWO is feasible to solve the sizing optimization problem of hybrid energy microgrid. And compared with the MOGWO, the DPSP and the REDR are reduced by $7.55 \%$ and $6.29 \%$, respectively, by using the IMOGWO.

In the planning and design of an actual island microgrid, selecting the optimal sizing allocation ratio of photovoltaic, photothermal, wind, diesel generator, and energy storage by the method described in this paper can meet the specific requirements of the project planning for comprehensive economy cost, DPSP, and REDR, which can provide theoretical basis and technical support for the planning and construction of island microgrid. Thus, the problem of power shortage in island areas can be effectively solved, and the cost of power supply in island areas can also be reduced. Since the basic data used in this paper are solar radiation and wind speed, the optimal sizing method described in this paper is also applicable to other island microgrids.

\section{Data Availability}

The data used to support the findings of this study are included within the article.

\section{Conflicts of Interest}

The authors declare that they have no conflicts of interest to report regarding the present study.

\section{Acknowledgments}

This work is supported by the $\mathrm{PhD}$ Research Start-Up Foundation of Hubei University of Technology (No. BSQD2019011) and Open Foundation of Hubei Key Laboratory for High-Efficiency Utilization of Solar Energy and Operation Control of Energy Storage System (No. HBSEES202005). 


\section{References}

[1] M. Farrokhabadi, C. A. Canizares, J. W. Simpson-Porco et al., "Microgrid stability definitions, analysis, and examples," IEEE Transactions on Power Systems, vol. 35, no. 1, pp. 13-29, 2020.

[2] B. Sang, T. Zhang, Y. Liu, Y. Chen, L. Liu, and R. Wang, "Energy management system research of multi-microgrid: a review," Proceedings of the CSEE, vol. 40, no. 10, pp. 30773093, 2020.

[3] I. Gonzalez, A. J. Calderon, and J. M. Andujar, "Novel remote monitoring platform for RES-hydrogen based smart microgrid," Energy Conversion and Management, vol. 148, pp. 489-505, 2017.

[4] D. F. Yang, C. Jiang, and G. W. Cai, "Multi-objective optimal configuration of AC/DC microgrid considering electricity/heat coupling," Automation of Electric Power Systems, vol. 44, no. 8, pp. 124-136, 2020.

[5] X. Y. Ma, Y. W. Wu, H. L. Fang et al., "Optimal sizing of hybrid solar-wind distributed generation in an islanded microgrid using improved bacterial foraging algorithm," Proceedings of the CSEE, vol. 31, no. 25, pp. 17-25, 2011.

[6] Y. Fu, Y. L. Jiang, and Z. K. Li, "Optimal allocation of distributed generation for microgrid based on hybrid quantum genetic algorithm," Power System Protection and Control, vol. 41, no. 24, pp. 50-57, 2013.

[7] P. Xie, Z. X. Cai, P. Liu et al., "Cooperative optimization of energy storage capacity for renewable and storage involved microgrids considering multi time scale uncertainty coupling influence," Proceedings of the CSEE, vol. 39, no. 24, 2019.

[8] X. Li, J. Fang, S. Guo et al., "Capacity sizing optimal for gridconnected micro-grid based on sensitivity analysis," Power System Protection and Control, vol. 46, no. 23, pp. 8-17, 2018.

[9] A. Kaabeche, S. Diaf, and R. Ibtiouen, "Firefly-inspired algorithm for optimal sizing of renewable hybrid system considering reliability criteria," Solar Energy, vol. 155, pp. 727-738, 2017.

[10] B. Zhao, X. Zhang, P. Li, K. Wang, M. Xue, and C. Wang, "Optimal sizing, operating strategy and operational experience of a stand-alone microgrid on Dongfushan Island," Applied Energy, vol. 113, pp. 1656-1666, 2013.

[11] L. Bukar, C. W. Tan, and K. Y. Lau, "Optimal sizing of an autonomous photovoltaic/wind/battery/diesel generator microgrid using grasshopper optimization algorithm," Solar Energy, vol. 188, pp. 685-696, 2019.

[12] F. K. Abo-Elyousr and A. Elnozahy, "Bi-objective economic feasibility of hybrid micro-grid systems with multiple fuel options for islanded areas in Egypt," Renewable Energy, vol. 128, pp. 37-56, 2018.

[13] L. Olatomiwa, R. Blanchard, S. Mekhilef, and D. Akinyele, "Hybrid renewable energy supply for rural healthcare facilities: an approach to quality healthcare delivery," Sustainable Energy Technologies and Assessments, vol. 30, pp. 121-138, 2018.

[14] E. S. Oda, A. M. A. E. Hamed, A. Ali, A. A. Elbaset, M. A. E. Sattar, and M. Ebeed, "Stochastic optimal planning of distribution system considering integrated photovoltaic-based DG and DSTATCOM under uncertainties of loads and solar irradiance," IEEE Access, vol. 9, pp. 26541-26555, 2021.

[15] J. H. Zhang, L. Yu, and N. Liu, "Capacity configuration optimization for island microgrid with wind/ photovoltaic/ diesel/ storage and seawater desalination load," Transactions of China Electrotechnical Society, vol. 29, no. 2, pp. 102-112, 2014.
[16] Y. Z. Li, X. J. Guo, and H. Y. Dong, "Optimal capacity configuration of wind/PV/storage hybrid energy storage system in microgrid," Proceedings of the CSU-EPSA, vol. 32, pp. 123$128,2020$.

[17] M. G. Abidi, M. Ben Smida, M. Khalgui, Z. Li, and T. Qu, "Source resizing and improved power distribution for high available island microgrid: A case study on a Tunisian petroleum Platform," IEEE Access, vol. 7, pp. 22856-22871, 2019.

[18] T. Tsai, T. M. Beza, W. B. Wu, and C. C. Kuo, "Optimal configuration with capacity analysis of a hybrid renewable energy and storage system for an island application," Energies, vol. 13, no. 1, p. $8,2020$.

[19] W. K. Liu, D. Wang, and X. D. Yu, "Multi-objective planning of micro energy network considering P2G-based storage system and renewable energy integration," Automation of Electric Power Systems, vol. 42, no. 16, 2018.

[20] L. Zhao, J. F. Dai, and J. Y. Meng, "Analysis on output characteristics of concentrating solar power system in various operating modes," Computer Simulation, vol. 34, no. 8, 2017.

[21] G. Ampuno, J. Lata-Garcia, and F. Jurado, "Evaluation of energy efficiency and the reduction of atmospheric emissions by generating electricity from a solar thermal power generation plant," Energies, vol. 13, no. 3, p. 645, 2020.

[22] J. Chen, J. Z. Liu, W. J. Shen, Z. Junhu, and C. Kefa, "Status quo in research of solar energy thermal power generation system," Thermal Power Generation, vol. 41, no. 4, pp. 17-22, 2012.

[23] J. F. Dai, Y. Tang, and L. N. Qu, "Research on coordinated optimization control of solar thermal and wind power generation," Computer Simulation, vol. 34, no. 10, pp. 73-77, 2017.

[24] L. Zhao, T. Shi, and B. Q. Shan, "Optimal allocation of heliostat field capacity for solar tower power plant," Renewable Energy Resources, vol. 36, no. 6, pp. 850-857, 2018.

[25] G. Dhiman, "MOSHEPO: a hybrid multi-objective approach to solve economic load dispatch and micro grid problems," Applied Intelligence, vol. 50, no. 1, pp. 119-137, 2020.

[26] S. Y. Liu, B. Zhao, and X. J. Wang, "Capacity configuration model for robust optimization of stand-alone microgrid based on benders decomposition," Automation of Electric Power Systems, vol. 41, no. 21, 2017.

[27] Z. L. Lv, Y. Tan, and J. Li, "Multi-objective optimal sizing for distributed generation of isolated hybrid microgrid using Markov-based electromagnetism-like mechanism," Proceedings of the CSEE, vol. 37, no. 7, pp. 1927-1937, 2017.

[28] S. Mirjalili, S. M. Mirjalili, and A. Lewis, "Grey wolf optimizer," Advances in Engineering Software, vol. 69, pp. 46-61, 2014.

[29] Y. T. Zhao, J. C. Chen, and W. G. Li, "Multi-objective grey wolf optimization hybrid adaptive differential evolution mechanism," Computer Science, vol. 46, no. 11, pp. 83-88, 2019.

[30] S. Mirjalili, S. Saremi, S. M. Mirjalili, and L. D. Coelho, "Multiobjective grey wolf optimizer: a novel algorithm for multicriterion optimization," Expert Systems with Applications, vol. 47, pp. 106-119, 2015.

[31] "National Greenhouse data System," http://data.sheshiyuanyi .com/. 